\title{
CHALMERS
}

UNIVERSITY OF TECHNOLOGY
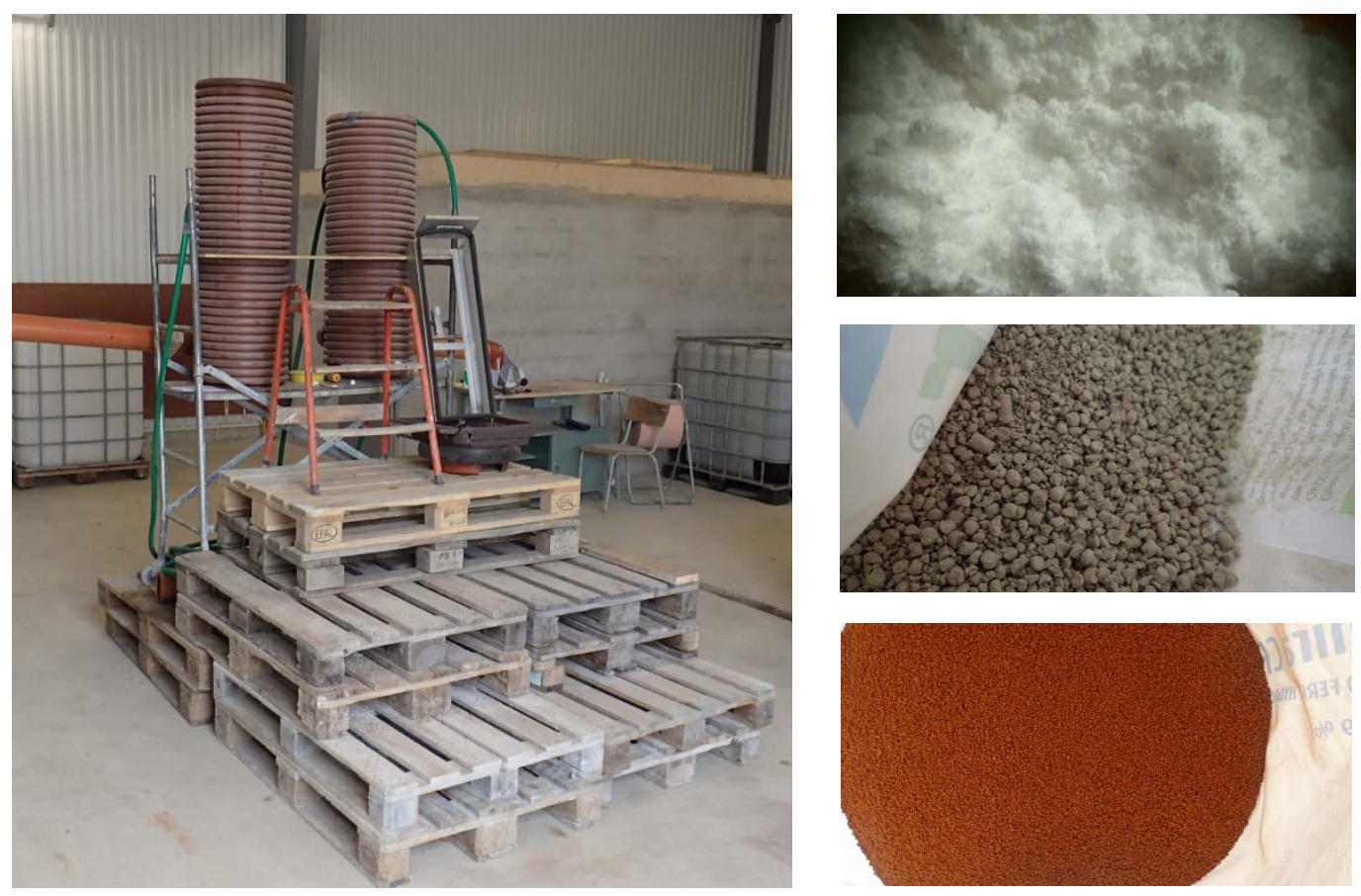

\section{Removal of heavy metals from}

\section{urban stormwater runoff by filtration through different filter materials}

Master of Science Thesis in the Master's programme Infrastructure and Environmental Engineering

ARMAND LLADONOSA FARRÉ 


\title{
Removal of heavy metals from urban stormwater runoff by filtration through different filter materials
}

\author{
Master of Science Thesis in the Master's programme Infrastructure and \\ Environmental Engineering
}

\author{
ARMAND LLADONOSA FARRÉ
}

Department of Civil Environmental Engineering CHALMERS UNIVERSITY OF TECHNOLOGY

Gothenburg, Sweden 2015 
Removal of heavy metals from urban stormwater runoff by filtration through different filter materials

Master of Science Thesis in the Master's programme Infrastructure and Environmental Engineering ARMAND LLADONOSA FARRÉ

(C) ARMAND LLADONOSA FARRÉ, 2015

Examensarbete 2015:127 / Institutionen för bygg- och miljöteknik Chalmers Tekniska Högskola 2015

Department of Civil Environmental Engineering

Division of water Environment Technology

Chalmers University of Technology

SE-412 96 Göteborg

Sweden

Telephone: +46 (0)31-7721000 
Removal of heavy metals from urban stormwater runoff by filtration through different filter materials

Master of Science Thesis in the Master's programme Infrastructure and Environmental Engineering ARMAND LLADONOSA FARRÉ

Department of Civil Environmental Engineering

Division of water Environment Technology

Chalmers University of Technology

\section{ABSTRACT}

In order to prevent the deterioration of water bodies, it is important to treat non-point sources, since they are considered one of the major pollution sources. The stormwater runoff flow generated under urban environments due to dry and wet depositions of contaminants gathers high concentrations of heavy metals, which can produce a pollution of the water bodies.

The different types of storm events over the Gothenburg area have been analysed, it was assumed that a gap of six hours was needed in order to finish a rain event. According to that more than the 70 $\%$ of the rain events are considered of low, which means than the mean intensity is $0.5 \mathrm{~mm} / \mathrm{h}$ and with and expected runoff flow in a $400 \mathrm{~m}^{2}$ area of $3 \mathrm{l} / \mathrm{min}$.

A synthetic stormwater has been created with lead, copper, zinc, nickel, cadmium and chromium in order to be able to run test simulations in two field trips. A total of three different filter cassettes with a total of five configurations have been analysed in 36 tests and 34 tests, respectively in the two field trips. Inside these filter cassettes a total of 11 different filter materials in several configurations have been analysed, they are considered "low-cost" since they are by-products of different industries sectors.

Although, these materials are able to achieve high uptake percentages for heavy metals according to laboratory experiments, the contact time is a limiting factor. This phenomenon was observed with the first test session where just dissolved heavy metals where used. On the second one, sediments where also used in order to perform a more realistic simulation and enhancing a physical retention of the particles added.

Different flow regimes were also analysed in the different tests and it is concluded that a lower flow leads to a major percentage uptake, since contact time is enhanced. Moreover, among all the materials analysed the one that performed the best has been the combination of pine bark and chitosan with an average of more than $20 \%$ of uptake in all the heavy metals systems, followed by peat as the second best filter material.

Key words: Stormwater, stormwater treatment, adsorption, heavy metals, uptake, "low-cost" filter materials 


\section{ACKNOWLEDGE}

Firstly, I would like to thank the possibility offered from Rent Dagvatten AB to be able to perform Master thesis with them. As an extension of that I would like to send an especial gratitude to Erik Bick, Rent Dagvatten CEO for the support provided because without his close work the aims and goals would not be achieved.

Secondly, I would like to thank Associate Prof. Sebastien Rauch for their tutored work along the whole research period and his implication on the samples analysis.

Finally, I also extend my greetings to my opponent colleagues and the rest of people that in minor or major measure has been involved in the project. 


\section{TABLE OF CONTENTS}

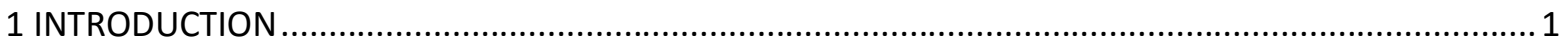

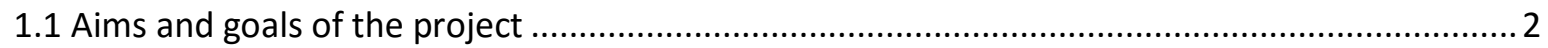

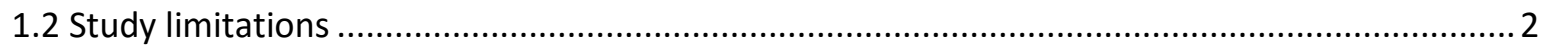

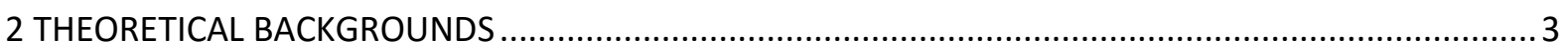

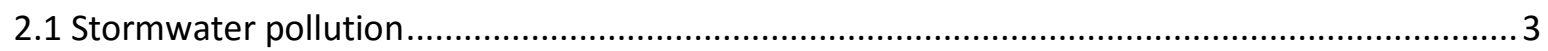

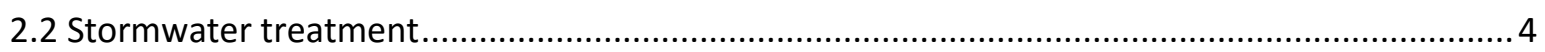

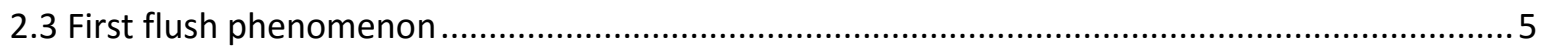

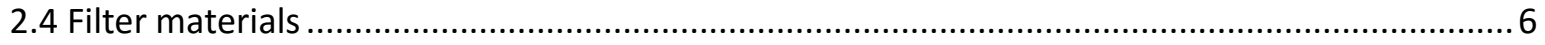

2.5 Potential heavy metal adsorption by filter materials ................................................................ 13

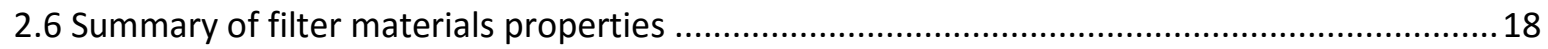

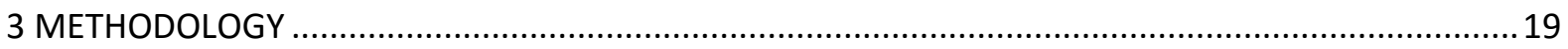

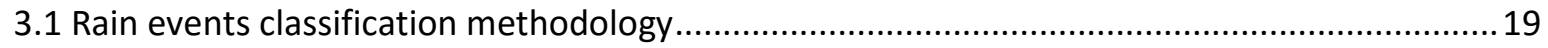

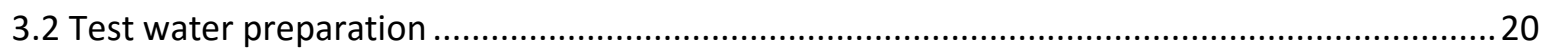

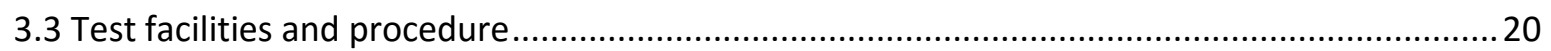

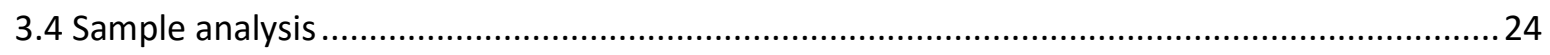

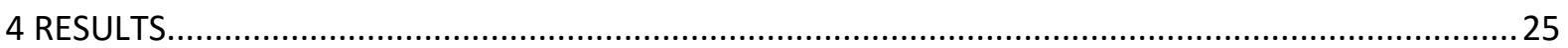

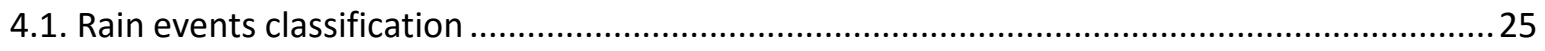

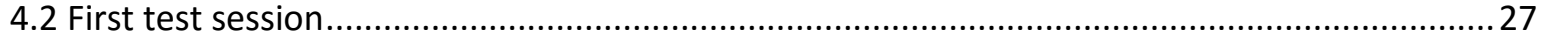

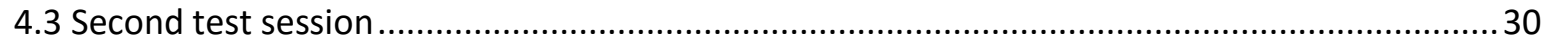

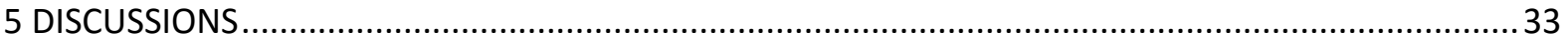

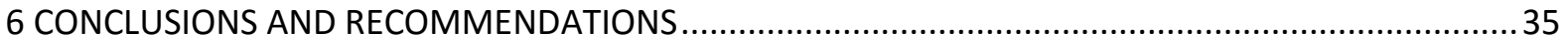

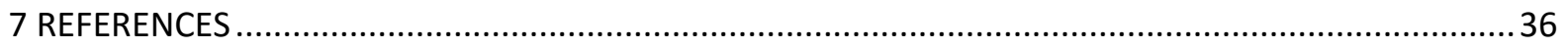

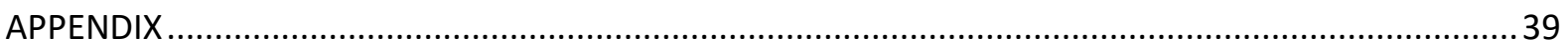




\section{LIST OF TABLES}

Table 1. Concentration ranges in stormwater runoff for different elements ...................................... 4

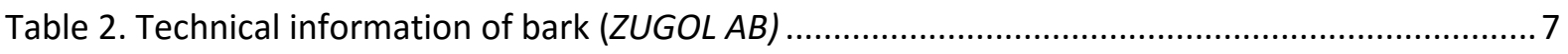

Table 3. Technical information of compacted ferric Hydroxide, CFH-12 (Kemira)...............................

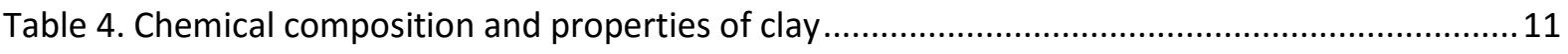

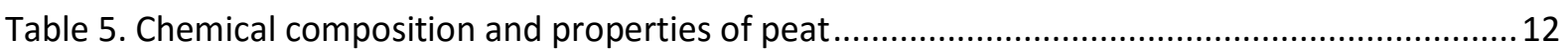

Table 6. Chemical composition and properties of Absol .................................................................12

Table 7. Equilibrium time, removal sequence and optimum pH for the different materials ...............18

Table 8. Weight of the different substances to obtain the concentration of the Heavy metals ..........20

Table 9. Application of the rational method to compute the equivalent intensity..............................21

Table 10. Number of test in each type of filter cassettes and in which condition ................................24

Table 11. Number of events, mean duration $[\mathrm{h}]$ and mean accumulated precipitation $[\mathrm{mm}]$ from

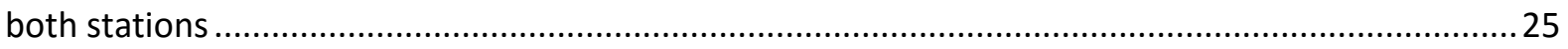

Table 12. Mean, maximum and minimum intensity values for the three types and two stations .......26

Table 13. Description of the filter material content tested and test number ......................................27

Table 14. Maximum uptake percentage achieved in each heavy metal and test number...................28

Table 15. Description of the filter material content tested and test number. .....................................30

Table 16. Maximum uptake percentage achieved in each heavy metal and test number...................30 


\section{LIST OF FIGURES}

Fig. 1. Pine bark

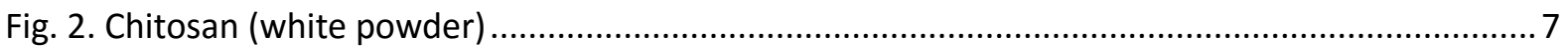

Fig. 3. Unload PUFs from less to more PPI (20, 30, 45 PPI) (left to right). Activated carbon load PUF

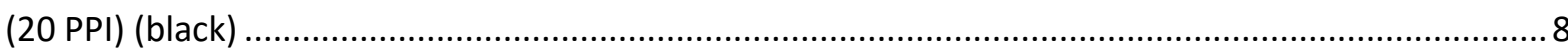

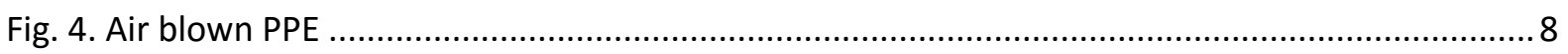

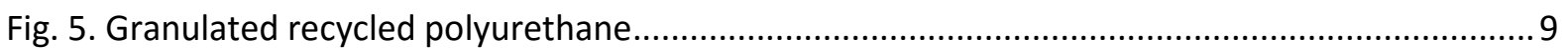

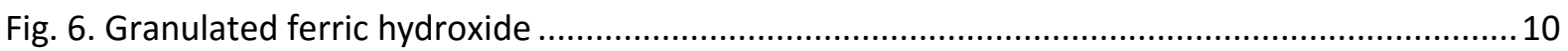

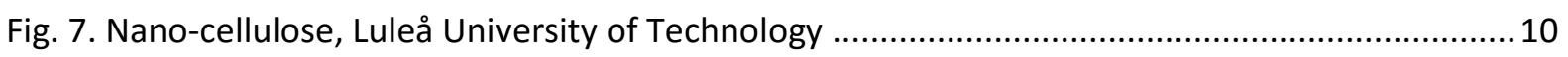

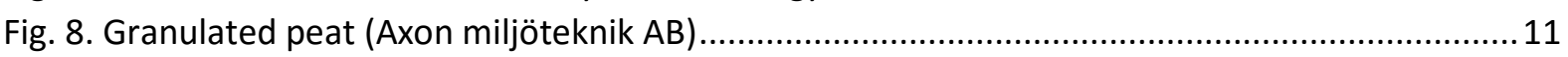

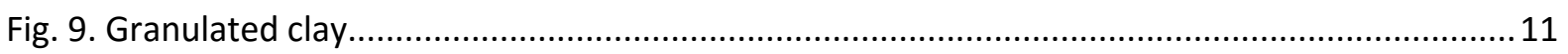

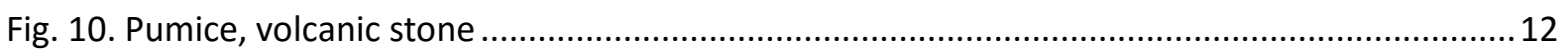

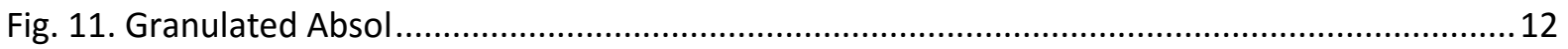

Fig. 12. Location of the two data collecting points, Gothenburg …................................................19

Fig. 13. Rent Dagvatten inside facilities in Flen. Simulation of the two wells .......................................2 21

Fig. 14. Left: Absorbenta filter cassette [Source: www.absorbenta.se] / Right: FlexiClean filter

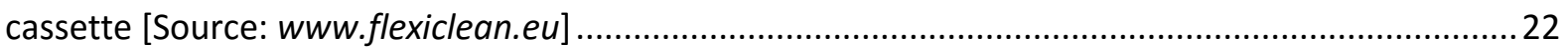

Fig. 15. Left: Modified FlexiClean filter cassette before sealing sides (A1) / Right: Second modification

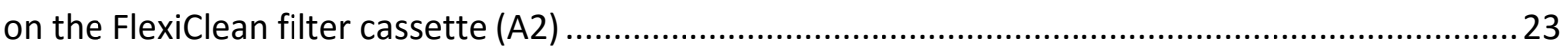

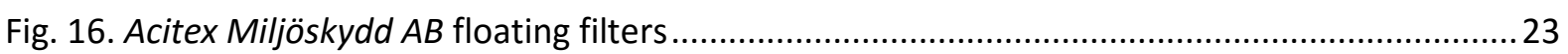

Fig. 17. Mean intensity and duration from the different events for the Lejonet Skansen station

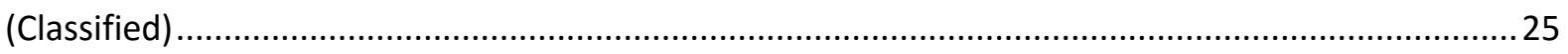

Fig. 18. Number of events of each type and percentage from the total amount .............................26

Fig. 19. Average, minimum and maximum of intensity ranges of each type of storm .........................27

Fig. 20. Retention percentage of each metal with pine bark and all the cassettes, tests $\# 1, \# 13$, \#22

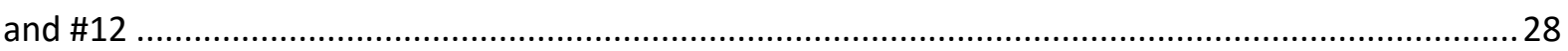

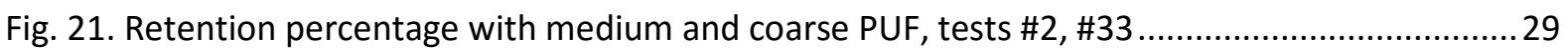

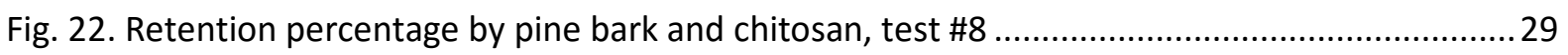

Fig. 23. Retention percentage by pine bark and peat, tests \#16 and \#26 ........................................... 31

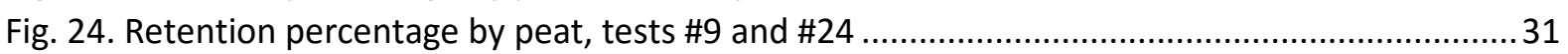

Fig. 25. Retention percentage by pine bark and chitosan, tests \#8 (first test session), \#31 and \#32 ..32

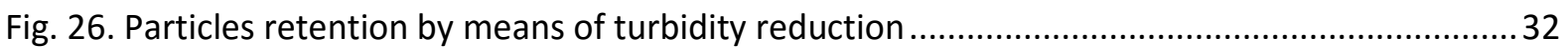




\section{INTRODUCTION}

In 2000 the Europe Union approved what is called the European Water Framework Directive (WFD Directive 2000/60/EC), which has been adapted to the Swedish legislation as Vattendirektivet. The main goal of the directive is to achieve a good state of all the waters bodies (surface, coastal and ground water) by 2015 , by promoting a sustainable use of the resource. This goal is achieved by preventing the deterioration of the water masses, improving and regenerating the water bodies in both ecological and chemical senses and finally by progressively reduce the contamination from discharges and emissions of priority substances by 2020. The Europe union commission listed a set of prior substances or group of substances (Decision 2455/2001/EC), which are characterised by their potential risk for water or the aquatic environment.

Under this directive, a great amount of infrastructures have been promoted in order to ensure that the receiving waters do not get deteriorated. The major part of the infrastructures, known as end-ofpipe solutions, have as objective to reduce, retain or remove the pollution load of the urban water from point sources, which have been considered as one of the major threat (Björklund, 2011). However, the point sources e.g. wastewater treatment plant outflow, are not the unique hazard. The so-called non-point pollution sources have been identified as another main actor regarding the quality deterioration of the receiving waters. This contamination discharge is originated during rain events by means of the urban water runoff and generated due to the different human activities that occur in an urban environment (Björklund, 2011; Lee \& Bang, 2000; Davis, et al., 2001). Regarding the urban water runoff, the list of priority substances to be reduced or removed has been updated with more elements and parameters (Eriksson, et al., 2007).

For that reason, although the WFD does not explicitly establish a procedure on how to treat these non-point sources, it has been recognised that the achievement of the main goal requires taking care of the storm water pollution (Björklund, 2011). This treatment has to be addressed from an efficient, economically and environmental point of view as the directive of the quality standards states (Directive 2008/105/EC). However, this might not be achieved by the common management practises, such as ponds or bio retention areas, in those densified areas (Björklund, 2011). Therefore, further management solutions, such on site treatment control points have to be implemented since the problem cannot be address by the more extend practices.

The lack of integration of sustainable stormwater management within the contemporary urban planning has increased the problems associated with the polluted water drainage from impervious surfaces in urban areas (Cettner, et al., 2013). Moreover, the effects of the climate change have increased these problems concerning the amount of pollutants and their transport capacity (Borris, 2013). Therefore, a good estimation of the urban stormwater pollutant loads has to be done in order to design and find the best mitigation and management strategy that minimize the impact on the receiving waters (Vaze \& Chiew, 2003).

Under these previous premises and with the main goal in mind, Rent Dagvatten provides a complete service to the interested costumers that cover the whole process. The best sustainable solution is found by doing an exhaustive analysis of the required needs as first step. Then multiple possible solutions are studied, and finally the best one is implemented and maintained over the exploitation period. Nowadays, Rent Dagvatten is involved in an interesting and ambitious project trying to design a standard test procedure for testing different filter cassettes in wells and different filter materials to target heavy metals, phosphorus (P) and PAH (Polycyclic Aromatic Hydrocarbons) from stormwater. 


\subsection{Aims and goals of the project}

This Master thesis project aims at assessing the uptake of heavy metals from stormwater by filter cassettes. The study has the following objectives:

- Firstly, the different rain events that can be encountered in the Gothenburg area are studied and classified.

- Secondly, stormwater is characterised.

- Thirdly, the heavy metals uptake percentage on Lead (Pb), Copper (Cu), Zinc (Zn), Nickel (Ni), Chromium $(\mathrm{Cr})$ and Cadmium (Cd), under different filter cassettes configurations, filter materials and flow regimes according to the rain classification.

\subsection{Study limitations}

The major limitation has been not having closer to Gothenburg the simulation facilities. To arrive to Flen is needed $4 \mathrm{~h}$ of car driving. This has been the major limitation since then the tests were concentrated in different short periods, instead of analysing them in a progressive way. 


\section{THEORETICAL BACKGROUNDS}

In this chapter the different theoretical concepts will be explained. First, there is the urban water runoff formation and characterisation. Second, the first flush phenomenon and third, a description of the filter materials used and a review on the existing literature regarding their potential on heavy metal retention.

\subsection{Stormwater pollution}

Urban stormwater runoff has been identified as one of the main pathways introducing non-point pollutants into receiving waters (Søberg, 2014; Davis, et al., 2001). This has been caused due to the development and urbanization, which affect both quantity and quality of urban runoff with higher volumes and higher pollutant loads (Göbel, et al., 2007). The causes of urban stormwater pollution have been studied extensively, leading to the conclusion that are related to human activities (Ahlman, 2006). Therefore, the intensity of land use, degree of imperviousness and soil type are factors that affect the urban stormwater generation. On the other side, climatic conditions such as rainfall intensity, duration and frequency are also important.

Atmospheric deposition has been proved for various authors that it is an important source of organic and inorganic contaminants to aquatic systems (Ahlman, 2006; German, 2003; Davis, et al., 2001). Atmospheric deposition can be divided into wet and dry deposition. Dry deposition is referred to the direct transfer of dust, aerosol and gas from the atmosphere to the ground (Göbel, et al., 2007). The particles with higher density fall down and accumulate on the urban surface. On the other hand, the wet deposition is due to rain and snow which contain substances leached out of the atmosphere.

Several authors have attempted to model the dry deposition, usually called build up models, by regression equations and process-based models (Borris, 2013), but the effort required might not be justified (Vaze \& Chiew, 2003). Moreover, it is also of interest the wash-off of those pollutants during rainfall events (Ahlman, 2006), mainly depending on the shear strength of flow and the impact of rainfall drops (Vaze \& Chiew, 2003). Those attempts have been promoted in order to be able to explain and quantify the first flush phenomenon, observed on the wash-off of dry deposition (Göbel, et al., 2007). However, this large scale engineering process is difficult to model due to the lack of data and interconnection between the different parameters (Vaze \& Chiew, 2003).

The U. S. Environmental Protection Agency (U. S. EPA) in the latest 1970s started the National Urban Runoff Program (NURP) establishing that heavy metals, such as $\mathrm{Cd}, \mathrm{Cu}, \mathrm{Pb}, \mathrm{Zn}, \mathrm{Cr}$ and $\mathrm{Ni}$, are the most prevalent priority pollutants found in urban stormwater (German, 2003; Søberg, 2014). Particles, nutrients and organic pollutants can also be found in stormwater apart from heavy metals (Ahlman, 2006). Moreover, the particles or suspended solids (SS) have a special interest since they act as a carrier for other pollutants.

The research in this thesis work is on heavy metals, since they can produce ecological degradation of receiving waters and can be really harmful for plants and humans due to the toxicity levels and degradation resistance (Søberg, 2014; Davis, et al., 2001). As trace some of them are essential to assure the correct function of the metabolism. However, it is when the concentration levels increase they lead to poisoning and can become a health threat due to bioaccumulation in the body and food chain (Ahlman, 2006). Basically, the toxic effects can be divided into acute, severe effects due to short-term exposure, and chronic, cumulative effects due to long-term exposure (Søberg, 2014).

The metal sources inside the urban environment are numerous and the metal release mechanisms are complex. However, building surfaces have been identified as an important source for $\mathrm{Pb}, \mathrm{Cu}, \mathrm{Zn}$ 
and $\mathrm{Cd}$, since they are easily removed in a soluble form from oxidised metal surfaces (Ahlman, 2006). Moreover, zinc concentration is also dependant of atmospheric deposition and traffic (German, 2003). Regarding copper, vehicle break emissions are also a great source apart from roof corrosion, since it is a well extend construction material for roofs (Davis, et al., 2001). On the other hand, lead concentrations still significant have a strong dependency on paint age and condition (Ahlman, 2006), although they have decreased since the lead phase was removed from petrol (German, 2003). Regarding cadmium, the major source is the wet atmospheric deposition (Davis, et al., 2001).

In the following table can be seen the variety on ranges in concentrations on urban stormwater runoff from each element according to different studies (Table 1). Finally, the stormwater runoff of contaminated water has a range of $\mathrm{pH}$ values of $4.5-8$ (Kalmykova, et al., 2008).

Table 1. Concentration ranges in stormwater runoff for different elements

\begin{tabular}{|c|c|c|c|c|c|}
\hline Lead, $\mathrm{Pb}$ & Copper, Cu & Zinc, Zn & Nickel, Ni & Chromium, $\mathrm{Cr}$ & Cadmium, Cd \\
\hline $5-200 \mu \mathrm{g} / \mathrm{I}^{\mathrm{a}}$ & $5-200$ & $000 \mu \mathrm{g} / \mathrm{I}^{\mathrm{a}}$ & 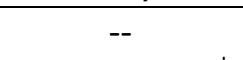 & 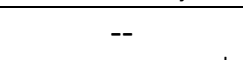 & $<12 \mu \mathrm{g} / \mathrm{I}^{\mathrm{a}}$ \\
\hline$<1-690 \mu \mathrm{g} / \mathrm{I}^{\mathrm{b}}$ & $\mu \mathrm{g} / \mathrm{I}^{\mathrm{b}}$ & $0.02-2000 \mu \mathrm{g} / \mathrm{l}^{\mathrm{b}}$ & $0.2-125 \mu \mathrm{g} / \mathrm{I}^{\mathrm{b}}$ & $0.1-222 \mu \mathrm{g} / \mathrm{I}^{\mathrm{b}}$ & $<0.1-15 \mu \mathrm{g} / \mathrm{I}^{\mathrm{b}}$ \\
\hline $2-525 \mu \mathrm{g} / \mathrm{I}^{\mathrm{c}}$ & $1-3416 \mu \mathrm{g} / \mathrm{l}^{\mathrm{c}}$ & $5-4880 \mu \mathrm{g} / \mathrm{l}^{\mathrm{c}}$ & $<1-70 \mu \mathrm{g} / \mathrm{l}^{\mathrm{c}}$ & $<2-50 \mu \mathrm{g} / \mathrm{l}^{\mathrm{c}}$ & $0.1-13 \mu \mathrm{g} / \mathrm{l}^{\mathrm{c}}$ \\
\hline
\end{tabular}

${ }^{a}$ (Davis, et al., 2001), ${ }^{b}$ (Søberg, 2014), ${ }^{c}$ (Göbel, et al., 2007)

\subsection{Stormwater treatment}

Several methods to treat stormwater have been proposed over the years. These different approaches to control pollution in stormwater are gathered under the term "best management practice (BMP)" (German, 2001). A stormwater best management practice is a technique, measure or structural control that is used to manage the quantity and improve the quality of stormwater runoff in a cost-effective manner.

The different measures can be divided into structural measures, which require changes in the drainage system and demand construction work to be implemented, or non-structural measures, which do not demand any change. Moreover, inside the structural solutions there are end pipe solutions, where the treatment facility is built just before the stormwater enters the receiving water body, and local solutions, which are used to reduce the amount of water that is run off (German, 2001). Another differentiation is between in-pipe or end-pipe measures, in-pipe refers to measures applied before water runoff enters the distribution network, while end-pipe refers to measures placed just before the realising of the water to the receiving body (Borris, 2013).

Among the different structural measures according to $\$ \varnothing$ berg (2014) are:

- Infiltration systems: permeable pavements, green roofs, blue roofs, vegetated filter strips and swales, infiltration trenches, infiltration surfaces and infiltration basins

- Detention systems: underground storage tanks

- Retention systems: wet stormwater ponds and dry retention ponds

- Vegetated systems: stormwater biofilters

- Filtration systems: sand filters

- Constructed stormwater wetlands.

The most used measures are underground retention tanks and ponds (German, 2003). The tanks are used to intercept the stormwater volume peak and deliver a uniform flow. These tanks can be built on concrete or by installing a small network of high diameter pipes that provides a large storage 
volume. Ponds are large retention areas, where sedimentation removal process of suspended solids and heavy metals is enhanced by decreasing the flow speed in a large extend.

Regarding the non-structural measures, the most common ones are street sweeping and filter insets for gully pots. Several studies have highlighted that stormwater quality can be improved by street sweeping, but the efficiency is dependent on the regularity and dry periods between rain events (German, 2003). On the other hand, filter insets are placed below road gullies in order to retain sediments and with that improve the stormwater quality (Makropoulos \& Butler, 2010). It is a source control in-pipe solution, which the main advantage is the small dimensions and the ability to be introduced easily inside the urbanized environment (Freni, et al., 2010). However, the need for regular maintenance is the main disadvantage (German, 2003).

Finally, due to the versatility achieved with this solution and the quickly introduction to highly dense urbanized areas without major interferences on the urban environment makes it extremely feasible to treat stormwater runoff before arriving to the distribution network.

\subsection{First flush phenomenon}

The first flush effect is a phenomenon that has increased the focus of attention. Several authors have tried to define it, but the notion of first flush is not yet clearly defined among the scientific community (Bertrand-Krajewski, et al., 1998). The treatment of urban runoff has been spread and put commonly in practice. However, in the search of efficient sustainable solutions has been noticed that a well understanding of the first flush phenomenon was required, in order to manage properly the wet weather flow in urban drainage systems (Deletic, 1998).

There is an extensively agreed qualitative description of the first flush phenomenon. There is first flush in urban water runoff exists when the first proportion of the discharge volume, contains the major proportion of the pollutant load that it will be transported during a single rain event (Bertrand-Krajewski, et al., 1998; Lee, et al., 2002). Therefore, if the first volume can be successfully intercepted will suppose a protection for the receiving waters (Bertrand-Krajewski, et al., 1998), since urban runoff and specially the first flush effect is one of the leading causes of water quality degradation at the beginning of a storm event (Lee, et al., 2002).

Another qualitative description states that the first flush phenomenon exists when the concentration peak appears before the runoff flow peak for a specific catchment and a singular rain event (Lee \& Bang, 2000). The U. S. EPA (1993) according to the previous definition established a methodology to design retention tanks, but without satisfactorily notion the first flush phenomenon (Bertrand-Krajewski, et al., 1998).

Several attempts to quantitative describe the first flush phenomenon are found in the literature, but none of them is predominant among the others. Bertrand-Krajewski (1998) reviewed those different attempts, including Stahre and Urbonas (1990) and Wanielista and Yousef (1993), who proposed $20 / 80$ and $25 / 50$ respectively, which means that the $80 \%$ of the total pollution load it is discharged during the first $20 \%$ of the total runoff volume. Moreover, Bertrand-Krajewski (1998) proposed a new approach 30/80 after revising the previous proposals. Deletic (1998) stated that the first flush is present when within the first $20 \%$ of the runoff the $20 \%$ of the pollutant load is exceeded, in other words the $20 / 20$.

The magnitude and strength varies among the different pollutants (Lee, et al., 2002). Apart from the different pollutants, other factors that affect the first flush are the catchment and rainfall characteristics (Deletic, 1998; Bertrand-Krajewski, et al., 1998) and the difference of behaviour 
between particulate or dissolved materials (Lee \& Bang, 2000). Among the rainfall characteristics, the rainfall intensity has been proved to be one of the most important parameters with strong relationship. On the other hand the antecedent dry weather period has been rejected as a significant parameter related to the first flush strength (Bertrand-Krajewski, et al., 1998). Moreover, the catchment size has an inverse relationship with the first flush intensity (Lee \& Bang, 2000; Lee, et al., 2002).

It has been noticed that the first flush effect is especially strong during the roof runoff regarding dissolved substances and heavy metals (Deletic, 1998). However, it cannot be said the same concerning the surface runoff since the phenomenon has not been studied that extensively due to the limited amount of reliable data on water quality over urban surfaces.

Finally, it is concluded that the first flush is complex and site specific phenomenon (Deletic, 1998). Furthermore, if it is perceived at the end of the drainage system, it is not likely to be caused by a first flush of pollution input into the system, the phenomenon might be caused by pollutant transformation and transport processes inside the drainage network.

\subsection{Filter materials}

In this chapter, it is going to be described the different filter materials used with some research and the information provided by the different suppliers. Most of them have been used in different areas and processes for removal of oil and petrochemical substances. However, just some of them have been used previously in water treatment as filters for removing heavy metals.

These filter materials are considered as "low-cost", since they are abundant and do not require almost any processing for being used (Bailey, et al., 1999). These sorbents have been investigated in order to be able to replace the actual costly methods for removing heavy metals.

\section{- $\quad$ Pine bark (ZUGOL AB)}

Pine bark is a natural product without any additions of chemical preparations. Therefore it is a biodegradable material and can be composted after use if the contamination levels are not higher enough to contaminate the soil. It has proved a high absorption capacity on different petroleum byproducts and cleaning fluids. Since, it does not absorb water it can be used as stormwater treatment filter material. Below, it can be seen an example of the material (Fig. 1).

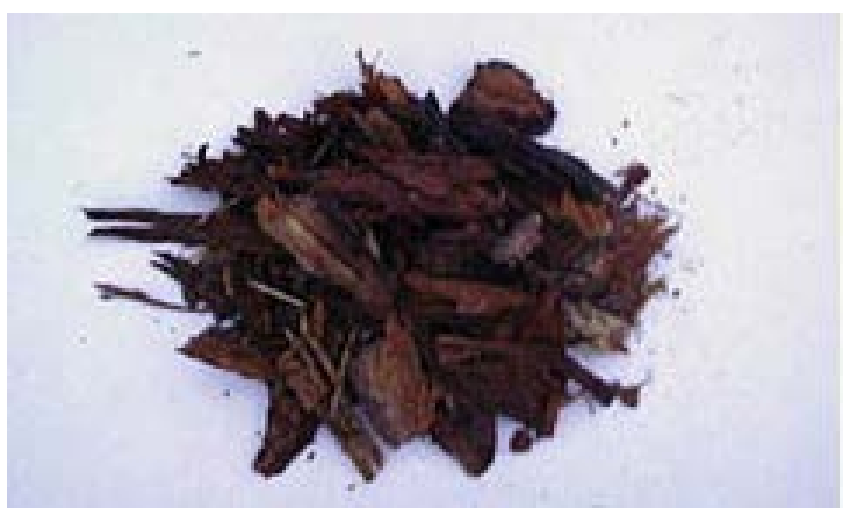

Fig. 1. Pine bark

In the following table there is described some technical information about the material (Table 2). 


\begin{tabular}{|l|l|l|}
\hline Content & Volume weight & Grain size \\
\hline $\begin{array}{l}85-90 \% \text { Pine bark (sorted, dried and granulate) } \\
10-15 \% \text { Pine wood }\end{array}$ & $0,25 \mathrm{Kg} / \mathrm{dm}^{3}$ & $\begin{array}{l}<0,25 \mathrm{~mm} \rightarrow 7,5 \% \\
>0,25 \mathrm{~mm}<5,0 \mathrm{~mm} \rightarrow 76,2 \% \\
>5,0 \mathrm{~mm} \rightarrow 16,3 \%\end{array}$ \\
\hline
\end{tabular}

\section{- Chitosan (BioLog Heppe GmbH)}

Chitosan is a polycationic polymer and waste product from the seafood processing industry and is an abundant natural resource, nontoxic and biodegradable. Chitosan is a polysaccharide obtained by deacetylating chitin which is the major constituent of the exoskeleton of crustaceous water animals and it is the second most abundant material in nature (Bailey, et al., 1999). Chelation or chelating agent is the property that makes it profitable, since chitosan can selectively bind desired materials such as cholesterol, fats and metal ions as several authors stated (Li, et al., 1992; Ravi Kumar, 2000). Chitosan is basically characterized by three properties: degree of acetylation, crystallinity and the polymer molecular weight (Pivarčiová, et al., 2014).

However, the filter material used is not just chitosan. It is mixed with bark in two different modalities. The first one is bark with chitosan plus chitosan sprayed and the second one is bark with sprayed chitosan. Below, it can be seen an example of the material (Fig. 2).

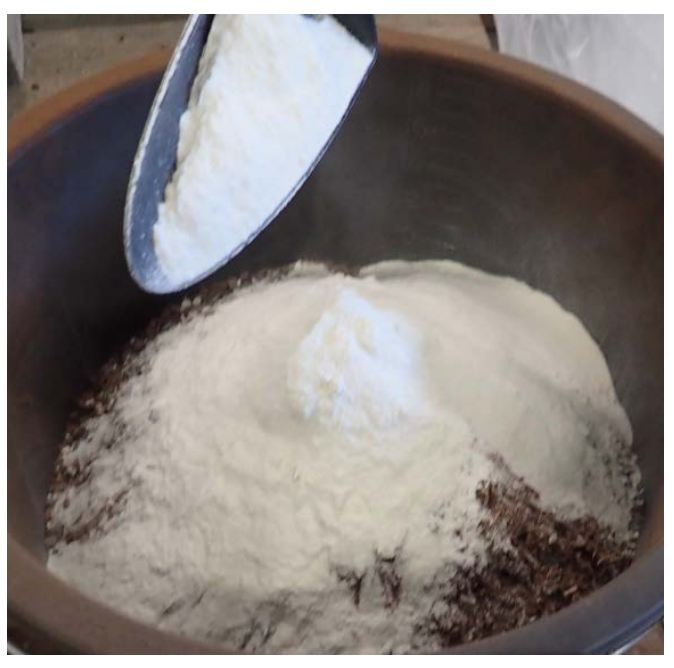

Fig. 2. Chitosan (white powder)

\section{- Unload Polyurethane foam (PUF) and activated carbon (AC) load PUF (EMW filtertechnik $\mathrm{GmbH})$}

Polyurethane foams can be either polyether or polyester type. However, polyether foams are better than polyester foams due to the hydrolysis resistance and other forms of chemical or environmental attack. Therefore, viscoelastic polyether foam products are used with great success in fish keeping and biological water treatment applications due to the outstanding resistance to acids and bases.

The foams can vary from open-cell or closed-cell polyurethane foams in all common densities. By means of the reticulation process after fabrication allows the pores opening of the foam. In other words, they can be considered as plastic material where a proportion of the solid phase is replaced by gas in the form of small bubbles (cells) (Lemos, et al., 2007). Various uniform configurations of open-cell pore structure with controlled pore spacing are available ranging from PPI 10 to PPI 80, where PPI stated for "Pores per Inch". 
The main characteristics are their resistance against high temperatures (up to $80{ }^{\circ} \mathrm{C}$ ), contain no plasticizers, manufactured in CFC-free foaming process and recyclable. Among the different application it is important to point out the odour absorption and wastewater treatment.

Regarding the activated carbon filter foam, it is impregnated with highly active carbon powder, granules or pellets. This impregnation maximizes the effective surface area of the filter medium without changing its volume. Approximately, 80 - 100 grams of activated carbon are impregnated per millimetre of material thickness and square metre of foam, providing a specific surface area of $900-1300 \mathrm{~m}^{2}$ per gram. In the following picture all four PUFs can be seen (Fig. 3).

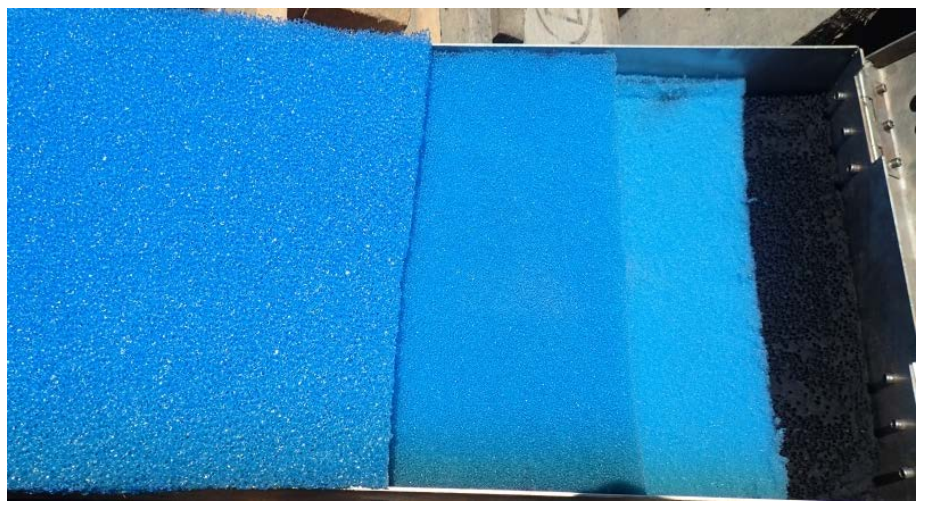

Fig. 3. Unload PUFs from less to more PPI (20, 30, 45 PPI) (left to right). Activated carbon load PUF (20 PPI) (black)

\section{- Air blown PPE (ACITEX Miljöskydd AB)}

The air blown PPE material is manufactured in round filters and also as different sized bags to be used in different filter cassettes and configurations.

This material targets the pollution that flows with the surface water, such as oils, chemicals, heavy metals in order to prevent the poisoning and the biological ecosystem of the receiving water. The different characteristics for air blown PPE to be considered a suitable filter material are: easy to use, no need for complicated fixed installations, no clogged filter cartridges and cheap filter changes. In the following picture an example of the material can be seen (Fig. 4).

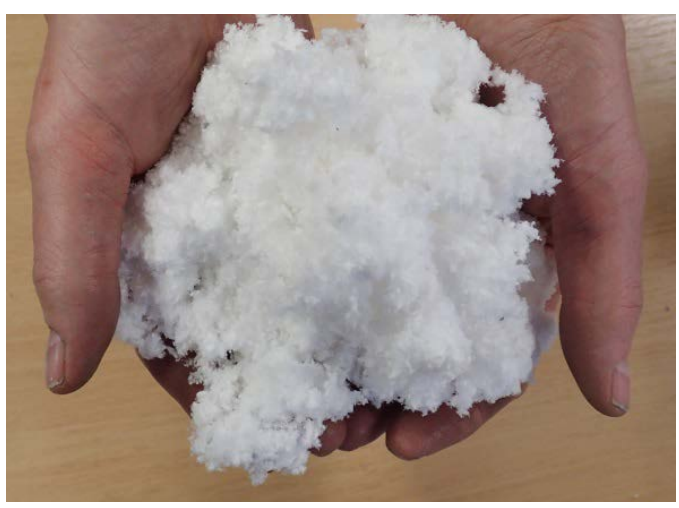

Fig. 4. Air blown PPE

\section{- Recycled polyurethane (ÖKO - pur, USG-Umweltservice GmbH)}

This material consists of $100 \%$ recycled polyurethane and it is supplied in two configurations; fine granules and powder. One of the benefits of this material is the high binding capacity although the area of use it is not commonly in water treatment. 
The finely granulated version of recycled polyurethane is used mostly for binding oil and chemicals on hard surfaces, such as roads, motorways or industrial sites (Apparent density, $415 \mathrm{~g} / \mathrm{l}$ ).

Recycled polyurethane as powder has a very fine pored structure, which makes it extremely fast acting. Wherever chemicals or oils have contaminated porous or rough surfaces, the powder configuration provides thorough, deep-down cleaning of these difficult surfaces. The low specificweight of the powder provides environmental benefits and facilitates to keep disposal costs down as well (Apparent density, $210 \mathrm{~g} / \mathrm{l}$ ). In the following figure the granulated recycled polyurethane can be seen (Fig. 5).

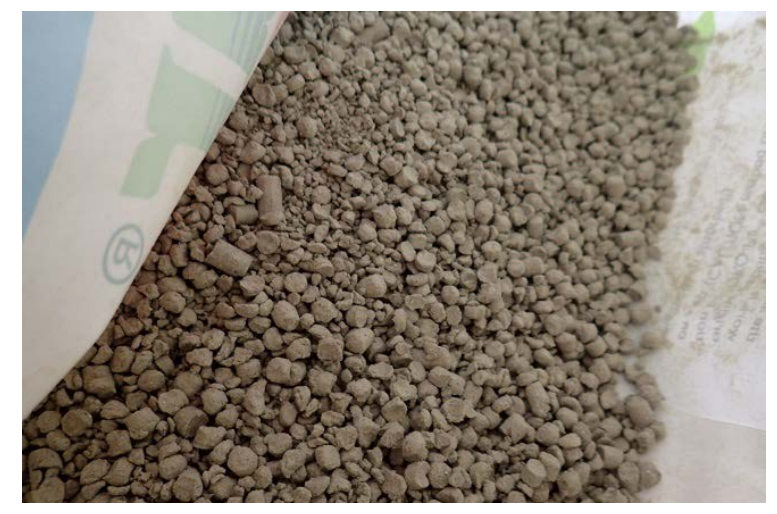

Fig. 5. Granulated recycled polyurethane

\section{- Compacted Ferric Hydroxide (CFH, Kemira)}

It is a granulate material, where the mainly content is $\mathrm{Fe}^{3+}$ concentration, around $44 \%$. It has been used previously as water treatment material, mostly in filter beds due to the ability of efficiently absorbing several metals. The process of adsorption consists of a gas or liquid (solute) that accumulates on the surface of a solid (absorbent), forming a molecular or atomic film (the absorbate). Among the benefits, it is important to highlight the high power of removal of impurities, easy to use, compact, low energy demand and small volumes of waste. On the other side, the drawbacks are that it can be costly, might have to be regenerated and the disposal of used media might be costly and have special regulations.

Moreover, this granulate does not dissolve in water. In the following table there is some technical information about the product (Table 3) and further down an image of the material (Fig. 6).

Table 3. Technical information of compacted ferric Hydroxide, CFH-12 (Kemira)

\begin{tabular}{|l|l|l|}
\hline Content & Bulk density & Grain size \\
\hline $44 \%$ Iron, $\mathrm{Fe}^{3+}$ & & $\begin{array}{l}2,0-0,85 \mathrm{~mm} \rightarrow 92,7 \% \\
<0,85 \mathrm{~mm} \rightarrow 5,9 \% \\
>2 \mathrm{~mm} \rightarrow 1,4 \%\end{array}$ \\
\hline
\end{tabular}




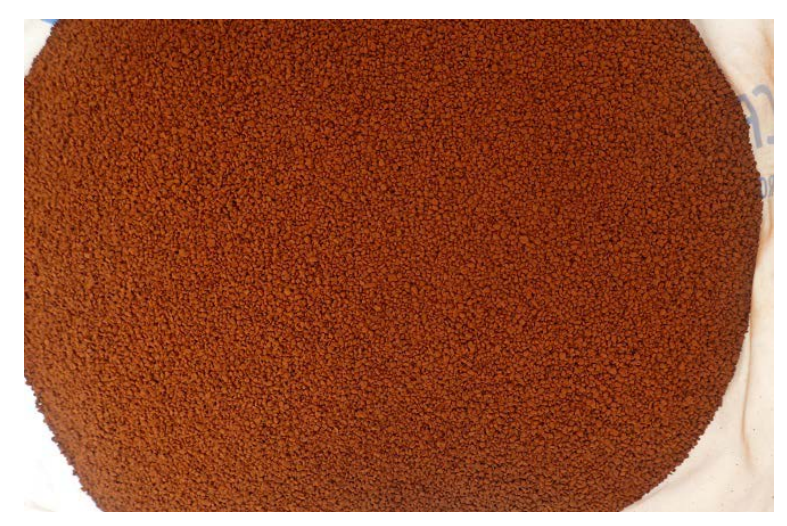

Fig. 6. Granulated ferric hydroxide

\section{- Nano-cellulose (NC)}

Any source of cellulose can be used to prepare nano-cellulose, but the most commonly used is the wood pulp. The process of confection consists on isolating the nano-cellulose fibrils from the woodbased fibres by mechanical methods.

Nano-cellulose (NC), whose cross section diameter is about 1-100 $\mathrm{nm}$ and the length is micron order of magnitude. In comparison with general cellulose fibres, NC has the advantages of high crystallinity, high surface area, unique optical properties, and high Young's modulus. Moreover, it shares the excellent characteristics of biological materials, such as light, degradable, biocompatibility and recyclable. Cellulose is easy to be wetted and has high water absorption (Cheng, et al., 2013).

In this case the NC material is provided by the Luleå University of Technology (Fig. 7).

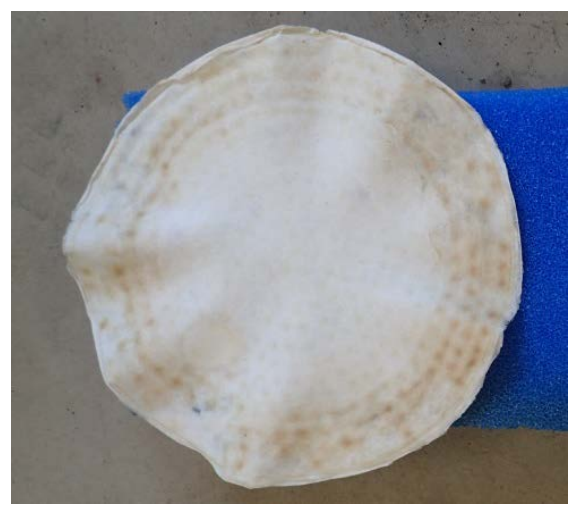

Fig. 7. Nano-cellulose, Luleå University of Technology

\section{- Peat (Axon miljöteknik AB)}

Peat basically consists of an accumulation of partially decayed vegetation or organic matter originated in natural areas called peatlands (Hugron, et al., 2013). The peatland ecosystem is considered the most efficient carbon sink, since peatland plants capture the $\mathrm{CO}_{2}$ which is naturally released from the peat and the equilibrium is maintained. Soils that contain mostly peat are known as histosols, which contains basically organic material. Peat is formed in wetland conditions, where a water flooding obstructs the arrival of oxygen from the atmosphere producing anaerobic conditions that decrease the decomposition rates.

Axon miljöteknik $A B$ provides peat in bags and in a granulated version as it can be seen in the following figure (Fig. 8). 


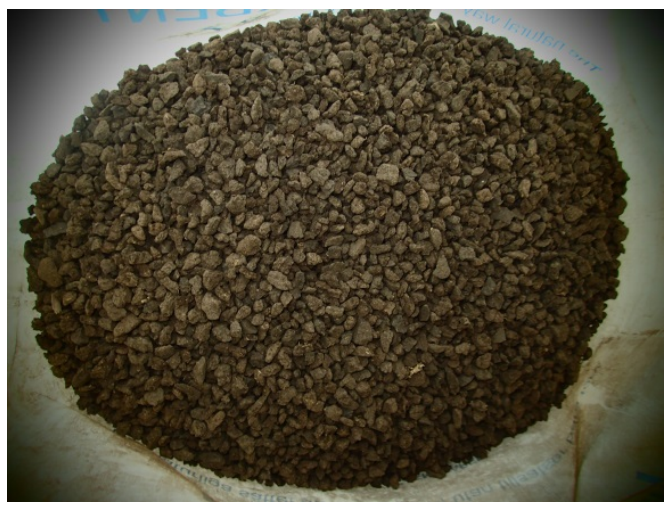

Fig. 8. Granulated peat (Axon miljöteknik AB)

- Clay granulated (Bara Mineraler AB)

Clay is a fine-grained natural rock or soil material that combines one or more clay minerals with traces of metal oxides and organic matter, the chemical content and other properties of the clay used can be seen in the table below (Table 4). Geologic clay deposits are mostly composed of phyllosilicate minerals with different amounts of water trapped in the mineral structure, due to the water content, clays are considered plastic materials.

Table 4. Chemical composition and properties of clay

\begin{tabular}{|c|c|c|c|c|c|c|c|c|c|}
\hline $\mathbf{S i O}_{2}$ & $\mathbf{A l}_{2} \mathbf{O}_{3}$ & $\mathbf{F e}_{2} \mathbf{O}_{3}$ & $\mathbf{K}_{\mathbf{2}} \mathbf{O}$ & $\mathbf{M g O}$ & $\mathbf{C a O}$ & $\mathbf{P}_{\mathbf{2}} \mathbf{O}_{5}$ & $\mathbf{p H}$ & Bulk density & Water content \\
\hline $67 \%$ & $14,6 \%$ & $5,6 \%$ & $3,5 \%$ & $1,6 \%$ & $0,9 \%$ & $0,1 \%$ & $5-6,5$ & $1150 \mathrm{Kg} / \mathrm{m}^{3}$ & $2-5 \%$ \\
\hline
\end{tabular}

Clays can be differentiated from other fine-grained soils by differences in size and mineralogy. The granulated clay used has a range of $2-6 \mathrm{~mm}$ of grain sizes. The material used can be seen in the following picture (Fig. 9).

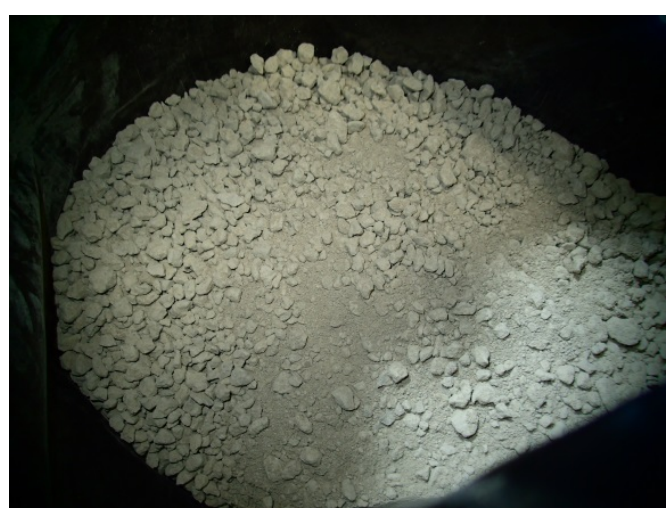

Fig. 9. Granulated clay

\section{- Pumice, volcanic stone (Bara Mineraler AB)}

Pumice is a volcanic rock that consists of highly vesicular rough textured volcanic glass, which may or may not contain crystals. Pumice is created when super-heated, highly pressurized rock is violently ejected from a volcano. The unusual foamy configuration of pumice happens because of simultaneous rapid cooling and rapid depressurization. In the following table the chemical content of the material can be seen (Table 5). 
Table 5. Chemical composition and properties of peat

\begin{tabular}{|c|c|c|c|c|c|c|c|c|}
\hline $\mathrm{SiO}_{\mathbf{2}}$ & $\mathbf{A l}_{2} \mathbf{O}_{3}$ & $\mathbf{F e}_{\mathbf{2}} \mathbf{O}_{\mathbf{3}}$ & $\mathbf{K}_{\mathbf{2}} \mathbf{O}$ & $\mathbf{M g O}$ & $\mathbf{C a O}$ & $\mathbf{P}_{\mathbf{2}} \mathbf{O}_{5}$ & $\mathbf{p H}$ & Bulk density \\
\hline $75,1 \%$ & $15,3 \%$ & $6,5 \%$ & $2 \%$ & $0,5 \%$ & $2,8 \%$ & $0,1 \%$ & 6,4 & $650 \mathrm{~kg} / \mathrm{m}^{3}$ \\
\hline
\end{tabular}

In the figure below, the material used can be seen (Fig. 10), the grain size used varies from $0.5 \mathrm{~mm}$ to $8 \mathrm{~mm}$.

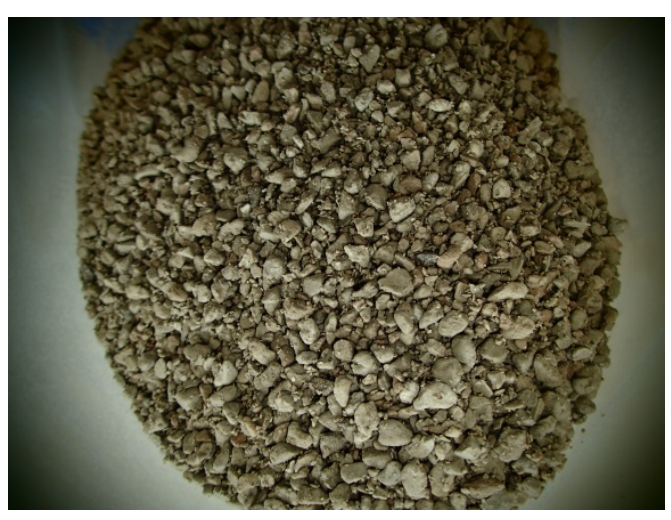

Fig. 10. Pumice, volcanic stone

- Absol (Yxhult Miljö AB)

The main ingredients forming Absol are sand, lime, cement and water. The ingredients are mixed and fermented mass with aluminum powder. The fermentation process provides to the material a high porosity. Finally, the product is crushed and sieved in various grain sizes and adapted to different uses. An example of the material can be seen in the following figure (Fig. 11).

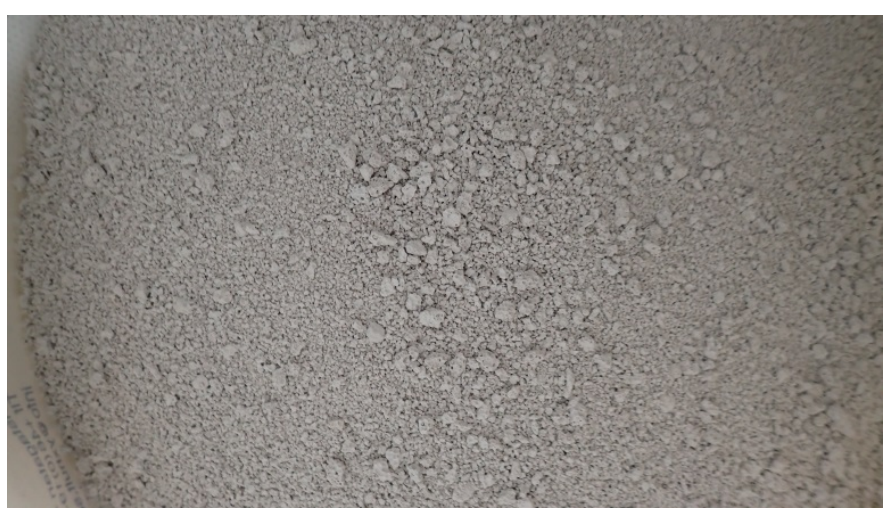

Fig. 11. Granulated Absol

The chemical composition and properties are described in the following table (Table 6).

Table 6. Chemical composition and properties of Absol

\begin{tabular}{|c|c|c|c|c|c|c|c|}
\hline $\mathrm{SiO}_{2}$ & $\mathrm{CaO}$ & $\mathrm{Al}_{2} \mathrm{O}_{3}$ & $\mathrm{Fe}_{2} \mathrm{O}_{3}$ & $\mathrm{MgO}$ & Soluble substances $^{\text {a }}$ & Grain size & Bulk density \\
\hline $50-55 \%$ & $24-28 \%$ & $3-6 \%$ & $1-2 \%$ & $0-1 \%$ & $2-3 \%$ & $0,5-5 \mathrm{~mm}$ & $400 \mathrm{Kg} / \mathrm{m}^{3}$ \\
\hline
\end{tabular}

${ }^{a}$ Calcium sulphate $\left(\mathrm{CaSO}_{4}\right)$ and alkali sulphate 


\subsection{Potential heavy metal adsorption by filter materials}

In this chapter a review of the existing literature regarding the potential on heavy metal retention by the different filter materials will be addressed.

The heavy metal removal via sorption is one of the most promising technologies for treating stormwater, since the traditional treatment methods to remove metals from aqueous solutions are not cost-efficient to remove low concentration of metal ions (Khorzughy, et al., 2015). Although there are several studies trying to find an effective filter media it is quite difficult to compare them from the literature. The comparison is not possible since sometimes the experiment conditions are not reported and just few of them are carried out with multiple heavy metal system or realistic experimental stormwater conditions (Genç-Fuhrman, et al., 2007).

Adsorption (or sorption) is the phenomenon where the dissolved molecules in water get attached to the surface of individual soil particles (Etutu Ngoh, 2006). In other words, can be said that the part of the solute (dissolved contaminant molecules) that gets attached to the sorbent (media where the particles are caught) form the sorbate (substance sorbed).

The surface attachment can be physical, chemical or exchange adsorption. The physical adsorption is produced by Van der Waals forces, which is a weak adsorption that can be separated easily. Chemical adsorption is formed by chemical bonding, the molecules absorbed are attached at specific reactive parts of the adsorbent surface and it is a strong union. Finally, the exchange adsorption is produced by electrical attraction between adsorbate and the surface (Etutu Ngoh, 2006).

\subsubsection{Pine bark}

Different studies have been done in order to determinate the potential on heavy metal adsorption by pine bark and the results showed and effective sorbent performance. Moreover, since it is a byproduct from sawmills, it is a cost-efficient material with very low environmental impact (Kalmykova, et al., 2008). The potential uptake has been achieved by means of batch and column experiments.

An experiment done by Täljemark, et al. (2004), pine bark material was tested against lead, copper and zinc with similar characteristics as the ones faced in the simulation. The researchers stated that the adsorption process is due to the ion exchange mechanism mostly. Moreover, the ion exchange in the metal uptake depends on the amount of exchangeable ions available. In pine bark calcium, potassium and magnesium are the ones with higher potential in this order.

The sorption capacity is not uniform among these three metals (Täljemark, et al., 2004). The best uptake metal was lead $\left(\mathrm{Pb}^{2+}\right)$, followed by copper $\left(\mathrm{Cu}^{2+}\right)$ and zinc $\left(\mathrm{Zn}^{2+}\right)$. Moreover, the uptake percentage decreases as the initial concentration of the dissolved metals increases. For lead the reduction is not that acute as the one experienced by copper and zinc. The main reason is because lead has high ability to form complexes and it binds harder to the active sites on the bark surface.

A previous research regarding the cadmium $\left(\mathrm{Cd}^{2+}\right)$ potential uptake using pine bark done by Al-Asheh \& Duvnjak (1997) stated that major uptake was achieved by using very fine pine bark particles, so the particle size has an important role. Moreover, the experiments revealed that the cadmium uptake was directly proportional to cadmium concentration and inversely proportional to the bark concentration with an equilibrium achieved after six hours of contact time. In other words, the major uptake is for low bark concentration and high cadmium concentrations. The cadmium uptake potential will be placed after lead and before copper, $\mathrm{Pb}^{2+}>\mathrm{Cd}^{2+}>\mathrm{Cu}^{2+}>\mathrm{Zn}^{2+}$. 
Many researchers have stated the binding of heavy metals is $\mathrm{pH}$ dependent. For cadmium the maximum uptake is achieved for a pH range of 4 to 5,5 (Al-Asheh \& Duvnjak, 1997). The tannin content is what provides bark the effectivity because it acts as weak acid ion exchange, in which the two hydrogen ions are replaced by each divalent ion and that is the reason why the $\mathrm{pH}$ decreases after adsorption (Bailey, et al., 1999). This phenomenon was confirmed by (Genç-Fuhrman, et al., 2007), since from eleven different sorbents the unique one that registered a reduction on $\mathrm{pH}$ was bark during batch experiments.

Finally, pine bark is a well investigated material that has proved a high adsorption capacity for several metal ions. The performance is even higher by decreasing particle size and pre-loading with another heavy metal ion. The tannin content is thought to be the main reason for such a good effectiveness (Kalmykova, et al., 2008).

\subsubsection{Chitin and Chitosan}

There are several studies that provide proof of the chitosan high adsorbent potential of heavy metals (Ravi Kumar, 2000). Moreover, it is chitosan once it is deacetylated from chitin due to the exposed free amino groups that chelates (see 2.3) up to five or six time more than chitin. Polysaccharides with a $50 \%$ of deacetylation seem to be the most effective to adsorption, but since it is high soluble in water and acidic media (Rinaudo, 2006) provides some applicable problems that can be solve by crosslinking the polymer with glutaraldehyde, although the performance is affected. Therefore, the chitosan performance varies with crystallinity, affinity for water, percent of deacetylation and amino group content. (Bailey, et al., 1999). Another parameter that affects the sorption capacity is the particle size. A perceptible uptake increase is associated with a decrease of particle size (Jha, et al., 1988).

Although chitosan has good complexing ability, the chelation process depends on the physical state of chitosan (powder, gel, fiber). Moreover, the chelation is also higher as greater the deacetylation degree of chitin (Rinaudo, 2006). This affirmation was earlier contrasted by (Kurita, et al., 1979) analysing the uptake performance of chitin on mercury $\left(\mathrm{Hg}^{2+}\right)$ and copper $\left(\mathrm{Cu}^{2+}\right)$ removal under different degrees of deacetylation. Furthermore, the interaction mechanism is dependant of the cation nature. The affinity of chitosan to uptake heavy metals can be graded as $\mathrm{Cu}^{2+}>>\mathrm{Zn}^{2+}>\mathrm{Cd}^{2+}>$ $\mathrm{Cr}^{3+}>\mathrm{Ni}^{2+}$ for divalent and trivalent cations (Rinaudo, 2006).

A complementing study done by Pivarčiová, et al. (2014) analysed the nickel $\left(\mathrm{Ni}^{2+}\right)$ uptake achieved by chitosan on batch experiments under aerobic conditions and ambient temperature. The equilibrium point of uptake was achieved after $14 \mathrm{~h}$ with $84 \%$, but with the first 15 minutes an uptake of around $50 \%$ was reached. This behaviour agrees with the sorption kinetics described by Jha, et al. (1988), which stated that the beginning fast uptake is driven by the amino groups and later it is reduced since the binding of cadmium is done by the formation of complexed metal ions. Moreover, a certain degree of protonation enhanced the adsorption on chitosan. The $\mathrm{pH}$ and metal concentration also affect the performance concluding that the metal uptake is less with a lower $\mathrm{pH}$ and increases as lower is the nickel initial concentration is (Jha, et al., 1988; Pivarčiová, et al., 2014).

Finally, it is important to highlight from the batch experiments done by Jha, et al. (1988) that the presence of calcium, magnesium and potassium affect less than $10 \%$ of the cadmium uptake. However, under the experiment conditions the presence of zinc supposed an effective competitive ion for cadmium removal. 


\subsubsection{Unload PUFs and AC load PUFs}

PUFs material is considered a good sorbent material in solid phase extraction (Lemos, et al., 2007). However, the unload PUFs present a major limitation, since only the metal ions after complex formation are going to be adsorbed. For a further adsorption process it is required to load the PUF matrix in order to widen the range of field applications (Lemos, et al., 2007). This is obtained by loading the structure in this case with activated carbon, but other loading materials could make it available for treat aqueous solutions containing heavy metals (Li \& Liu, 2012).

\subsubsection{Granulated Ferric Hydroxide (GFH)}

One of the major reported uses of Granulated Ferric Hydroxide (GFH) is for remove arsenate (GençFuhrman, et al., 2007). However, on the research done by Genç-Fuhrman, et al. (2007), this filter material was tested simultaneously against $\mathrm{As}, \mathrm{Cd}, \mathrm{Cr}, \mathrm{Cu}, \mathrm{Ni}$ and $\mathrm{Zn}$ on batch experiments within other ten sorbents. The general performance was rated as one of the best with especially efficiency on chromium removal and still effective for cadmium, nickel and zinc. Furthermore, the obtained results also put into evidence that the heavy metal removal increased as higher the initial concentration was in most of the batches.

During these batch experiments the $\mathrm{pH}$ was adjusted to 6,5 to resemble the lowest realistic stormwater runoff $\mathrm{pH}$, but at the experiment equilibrium, the $\mathrm{pH}$ was close to the point of zero charge (between 7,5-8 for this material). This fact indicates that both electrostatic attraction and formation of complexes on the sorbent surface are the removal mechanisms.

A couple of years later a research done by Wu \& Zhou (2009), confirmed the removal mechanisms and stated that the $\mathrm{pH}$ values of the sorption experiments were controlled in a major extend by the sorbents minerals and release of $-\mathrm{OH}$ groups as the complexes with heavy metals where formed. Furthermore, as the precipitation of heavy metal minerals/salts occur, indicates that the sorption removal process is no longer the primary.

A difference perceived between both studies, was that in the control batch involving the GFH some leaching of chromium and zinc was noticed in Wu \& Zhou (2009) research. Furthermore, these two studies slightly differ on the sequence of metal adsorption, which is $\mathrm{Cr}>\mathrm{Cd}>\mathrm{Zn}>\mathrm{Ni}>\mathrm{As}>\mathrm{Cu}$ and $\mathrm{Cd}>$ $\mathrm{Zn}>\mathrm{Ni}>\mathrm{Cu}>\mathrm{As}>\mathrm{Cr}$, according to the studies on chronologic order. The main difference is in chromium which might be related with the leaching perceived.

Another study done by Genç-Fuhrman, et al. (2008), a GFH sorbent was tested in column experiments to determine the potential removal of the same heavy metal systems. An increasing of the $\mathrm{pH}$ in equilibrium due to dissolution of sorbent minerals was confirmed in this study. Moreover, was also perceived the formation of heavy metal minerals/salts, so it was suggested that cadmium, copper and nickel could be removed by this mechanism. Finally, the sequence of metal uptake is different, but cannot be compared since the experiment set-up is not equal and column experiments usually report higher sorption capacities.

\subsubsection{Nano-cellulose (NC)}

A research done by Kardam, et al. (2014) studied the sorption potential of NC fibers against cadmium, nickel and lead with batch experiments under clean air-conditioned environmental laboratory. The initial concentration of the three divalent cations was varying from 1 to $50 \mathrm{mg} / \mathrm{l}$ and the uptake was increasing accordingly too, but no major uptake was achieved above $25 \mathrm{mg} / \mathrm{l}$ because as the initial concentration increases the binding sites became quickly saturated. The binding is enhanced by the large number of $-\mathrm{OH}$ free groups which enable the electrostatic 
interaction with the divalent cationic metal species. The ion binding is driven by the Van der Waals forces and the ion exchange process.

Moreover, the required time to reach the maximum sorption was determined to be $40 \mathrm{~min}$ and the nano-cellulose has the advantage that at least can be used in three cycles of sorption and desorption without a substantial decrease on the performance. Finally, the uptake sequence of the different divalent ions was $\mathrm{Pb}>\mathrm{Cd}>\mathrm{Ni}$, with sorption percentages higher than $85 \%$.

\subsubsection{Peat}

Peat has been studied for more than 25 years due to the high adsorption capacity for heavy metals in comparison with other natural adsorbent materials. The performance is dependent on the type of peat and solution characteristics ( $\mathrm{pH}$, ion concentration and ionic strength) (Kalmykova, et al., 2008). A research done by Liu (2008) studied the retention of copper, nickel and cadmium as single, double and triple component with batch experiments. Peat contains lignin and cellulose, but lignin contains polar functional groups such as acids, humic and fulvic (Sen Gupta, et al., 2009). Humic acid molecules in a spherical shape, which can form aggregates of porous with a very large specific surface area enhancing the removal of heavy metal ions by ion exchange, complexation and adsorption (Liu, et al., 2008). Unfortunately, it is not exactly well known how the metal ion binding in peat works (Sen Gupta, et al., 2009). However, the release of protons from peat provides more available adsorption sites for the heavy metal cations to get attached. Liu (2008) research also showed that the adsorption percentage increases up to $\mathrm{pH}$ values of $6-7$ and the equilibrium at the maximum uptake was reached after 20-60 minutes of contact time (Kalmykova, et al., 2008).

The uptake with double and triple components is lower than single components due to the repulsive electrostatic forces among ions. The competence between all three components produces a suppression effect with an affinity sequence of $\mathrm{Cu}^{2+}>\mathrm{Ni}^{2+}>\mathrm{Cd}^{2+}$. In other words, copper is favourable adsorbed on peat over nickel and cadmium while nickel is favoured adsorb over cadmium (Liu, et al., 2008). This was confirmed and increased by a research done by Kalmykova (2008), where peat was also tested against lead and zinc leading with a final sequence of $\mathrm{Pb}>\mathrm{Cu}>\mathrm{Ni}>\mathrm{Cd}>\mathrm{Zn}$. It was noticed that the measured cation exchange capacity was considerably lower than other peats used in the literature, the reason for that might be related to the degradation level. At higher levels of decomposition the fulvic acid presence is higher and the proton donation is the double in comparison to humic acid. Moreover, the initial concentration also affects the peat uptake. At low metal concentration metal ions are initially adsorbed, on the other hand, as the initial concentration increases the uptake decreases since the affinity sites become saturated (Kalmykova, et al., 2008). As the solution concentration increases the complexation binding process becomes dominant over the ion exchange (Bailey, et al., 1999).

\subsubsection{Granulated clay}

The adsorption potential of clay resides on the net negative charge on the structure of fine-grain silicate minerals (Bailey, et al., 1999). The negative charge structure is neutralised when positively charged species get attached such as heavy metal cations. Another advantage is the large surface area which provides a higher adsorption capacity. Therefore as smaller the crystal sizes are higher is the cation exchange capacity.

A research study done by Potgieter (2006) analysed the adsorption potential of clay in single metal solutions of lead, chromium, nickel and copper in batch experiments. For all the four cases, the equilibrium was reached quickly, with an average of 30 minutes, showing that the adsorption sites are well exposed. However, slightly equilibrium time variation is visible regarding the initial 
concentration of the metal solution, in other words, the equilibrium time is delayed with a higher metal concentration. Moreover, a higher initial concentration results in a higher amount adsorbed.

For all four metal systems, increasing the adsorbent mass has produced a major percentage uptake, since the adsorbent sites increased. However, especially for nickel and chromium the maximum uptake was reached quickly and for copper the percentage of uptake just showed a slightly increasing with more adsorbent presence (Potgieter, et al., 2006).

At low $\mathrm{pH}$ values, there is competition between the positively charged hydrogen ions and metal ions for the negatively charge adsorption sites on the clay surface. When the $\mathrm{pH}$ increases, the major presence of $\mathrm{OH}^{-}$produces a balanced situation so the metal ions can be adsorbed on the clay surface, so a major uptake is achieved. However, at slightly high $\mathrm{pH}$ values the precipitation of metal hydroxides may lead to a reduction of the metal ion adsorbed (Potgieter, et al., 2006). Generally, there is positive effect on the uptake percentage as $\mathrm{pH}$ increases. However, especially for lead and copper, there is a slightly reduction when $\mathrm{pH}$ is above the $7-8,5$ range. Finally, the adsorption metal affinity order is $\mathrm{Pb}>\mathrm{Cr}>\mathrm{Ni}>\mathrm{Cu}$ (Potgieter, et al., 2006).

\subsubsection{Pumice}

The properties that make volcanic rocks suitable for metal removal are the large surface area, high water adsorption capacity and a negatively charges surface (Alemayehu \& Lennartz, 2010).

A researches done by Alemayehu (2010) and Khorzughy (2015) analysed respectively the nickel and cadmium removal from aqueous solution using pumice in batch experiments. Independently of the initial concentration the equilibrium was reached after $120 \mathrm{~min}$ for Khorzughy (2015), while Alemayehu (2010) set the contact time to 24 hours with no significant increasing after 12 hours. It was showed in both studies that as the initial concentration increased the uptake achieved was higher, but the efficiency of the adsorption decreases.

Regarding the relation between the uptake and $\mathrm{pH}$, the major uptake is reached for a $\mathrm{pH}$ value of 6 . It is important to mention that over a $\mathrm{pH}$ value of 7 cadmium precipitates as hydroxide. Moreover, at low $\mathrm{pH}$ values the uptake is compromised for the competition between cadmium ions and the oxide groups of the adsorbent that are protonated (Khorzughy, et al., 2015). This was also visible in Alemayehu (2010), where the metal analysed was nickel instead of cadmium, in this case the optimal $\mathrm{pH}$ was between $4-6$ values.

Moreover, Alemayehu (2010) studied the competition between three different metal systems (nickel, cadmium and copper) where it was proved the competence between them by a significant reduction on the uptake percentage in comparison to single metal system conditions. Finally, the affinity sequence regarding the removal was established as $\mathrm{Cu}>\mathrm{Ni}>\mathrm{Cd}$. 


\subsection{Summary of filter materials properties}

As summary, in the following table there are gathered the equilibrium time and the affinity sequence of metal removal for the different materials analysed in the possible cases (Table 7). Moreover, the optimum pH is also included, but it might be related to just single metal system, so it is referred to a specific substance. Finally, the stormwater runoff of contaminated water has a range of $\mathrm{pH}$ values of 4,5-8 (Kalmykova, et al., 2008).

Table 7. Equilibrium time, removal sequence and optimum pH for the different materials

\begin{tabular}{|c|c|c|c|}
\hline Material & Equilibrium time $^{a}$ & Removal affinity sequence & Optimum $\mathrm{pH}^{\mathrm{b}}$ \\
\hline Bark & $6 \mathrm{~h}$ & $\mathrm{~Pb}>\mathrm{Cd}>\mathrm{Cu}>\mathrm{Zn}$ & $4-5,5$ \\
\hline Chitosan & $14 \mathrm{~h}$ & $\mathrm{Cu}>>\mathrm{Zn}>\mathrm{Cd}>\mathrm{Cr}>\mathrm{Ni}$ & $7-8,3$ \\
\hline PUFs & - & - & - \\
\hline GFH & $48 \mathrm{~h}$ & $\mathrm{Cr}>\mathrm{Cd}>\mathrm{Zn}>\mathrm{Ni}>\mathrm{Cu}$ & - \\
\hline Nano-cellulose & $40 \mathrm{~min}$ & $\mathrm{~Pb}>\mathrm{Cd}>\mathrm{Ni}$ & $6-6,5$ \\
\hline Peat & $20-60 \min$ & $\mathrm{Pb}>\mathrm{Cu}>\mathrm{Ni}>\mathrm{Cd}>\mathrm{Zn}$ & $6-7$ \\
\hline Clay & $20-35 \mathrm{~min}$ & $\mathrm{~Pb}>\mathrm{Cr}>\mathrm{Ni}>\mathrm{Cu}$ & $7-8,5$ \\
\hline Pumice & $120 \min$ & $\mathrm{Cu}>\mathrm{Ni}>\mathrm{Cd}$ & $4-6$ \\
\hline
\end{tabular}

${ }^{\text {a }}$ Time needed to achieve the maximum uptake

${ }^{\mathrm{b}}$ Optimum $\mathrm{pH}$ for a major uptake in all, some or single substances 


\section{METHODOLOGY}

\subsection{Rain events classification methodology}

In order to be able to categorize the different types of storm events, the data has been acquired from the Göteborgs Stad webpage. This data has been taken from two different locations, Femman huset and Lejonet Skansen which in following figure the location is highlighted over a map of Gothenburg (Fig. 12). The data used covers the years 2013-14, with an accuracy of one value every hour.

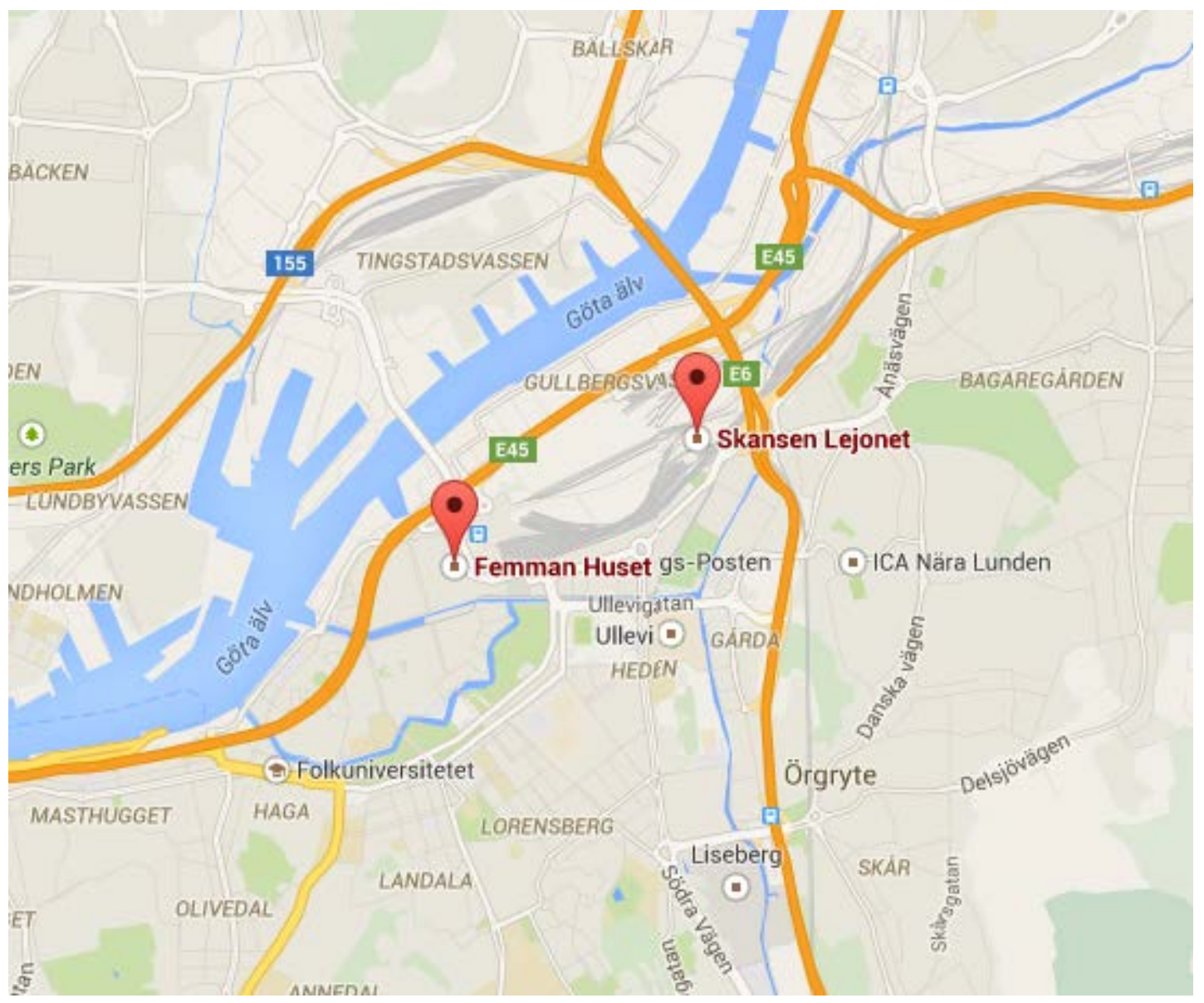

Fig. 12. Location of the two data collecting points, Gothenburg

The different storm events where defined as a rain period that it is separated for a gap equal or higher than 6 hours, between the preceding and succeeding rainfall (Huff, 1967). Then from the different events the accumulated precipitation in $\mathrm{mm}$ and duration time has been computed. Finally, the mean intensity of each event has been computed as follows (1).

$\bar{I}\left[\frac{\mathrm{mm}}{\mathrm{h}}\right]=\frac{\text { Accumulated precipitation }[\mathrm{mm}]}{\text { Total duration }[\mathrm{h}]}$

Once all the events are calculated, then is time to classify them. It has been assumed that from the mean duration time to the highest duration rain there are two standard deviations (2). $d$ stands for duration.

$2 \sigma=\max (d)-\operatorname{mean}(d) \rightarrow \sigma=\frac{1}{2} \cdot(\max (d)-\operatorname{mean}(d))$ 
For all the events it is computed the event duration $\left(d_{e v}\right)$, the accumulated precipitation per event $\left(P_{a c}\right.$ ev $)$. Moreover, it is also calculated the mean events duration $\left(d_{\text {mean }}\right)$ and the mean events accumulated precipitation $\left(P_{\text {ac mean }}\right)$.

The classification procedure has been done by dividing the storm events into heavy, normal or low storm as it follows,

- The heavy rain, it is referred to these type of events where the mean accumulated precipitation is exceeded in less time than the mean duration of the events.

$P_{\text {ac ev }}>P_{\text {ac mean }}$ in time duration, $t<d_{\text {mean }}$

- The normal rain, it is referred to these type of events where the mean accumulated precipitation is exceeded in less time that the mean duration time plus one standard deviation.

$P_{\text {ac ev }}>P_{\text {ac mean }}$ in time duration, $t<d_{\text {mean }}+\sigma$

- The low rain covers the rest of the cases, in other words the rest of the events.

\subsection{Test water preparation}

After an extensive review of the existing literature and different analysis reports of real stormwater samples provided by Rent Dagvatten, a plausible synthetic stormwater has been decided according to the information provided in the previous chapter (2.1).

The different metals element had to be diluted into an aquatic media in the Chalmers laboratory. In the following table there is explained from which substance the elements are provided and the required amount to obtain the desired concentration (Table 8). The scale used was calibrated and with a precision of $0,1 \mathrm{~g}$.

Table 8. Weight of the different substances to obtain the concentration of the Heavy metals

\begin{tabular}{|l|l|c|c|}
\hline Element & \multicolumn{1}{|c|}{ Substance } & $\begin{array}{c}\text { Concentration in synthetic } \\
\text { stormwater }[\mu \mathrm{g} / \mathrm{I}]\end{array}$ & $\begin{array}{c}\text { Amount of } \\
\text { substance [g] }\end{array}$ \\
\hline Lead & Lead (II) nitrate & 50 & 0.40 \\
\hline Copper & Copper (II) sulfate & 200 & 2.5 \\
\hline Zinc & Zinc chloride & 1000 & 10.4 \\
\hline Nickel & Nickel chloride & 70 & 0.4 \\
\hline Chromium & Chromium chloride (tetra-hydrate) & 70 & 0.4 \\
\hline Cadmium & Cadmium chloride & 1.5 & 8.0 \\
\hline
\end{tabular}

The different amounts were added to a five liters bottle, in which to provide the desired concentration into 500 liters of synthetic stormwater tank, it was needed to add $500 \mathrm{ml}$ of the mixture.

\subsection{Test facilities and procedure}

The tests were run in Flen (Södermanland, Sweden), where Rent Dagvatten has installed the simulation of two wells. Two sessions of tests have been done with Erik Bick (CEO, Rent Dagvatten). The first one, 36 tests were run with no particles just dissolved metals. In the second one, 34 tests were run with particles collected from placed filters in Gothenburg that were obtained during a maintenance session. In the following picture (Fig. 13), it can be seen the simulation workplace with the two wells.

The tests were run by pumping synthetic stormwater from one tank to the other and letting the water go through the filter cassette. There are three types of pumps available, one small which it is 
able to provide a flow of $13 \mathrm{l} / \mathrm{min}$, a second one with a capacity of $60 \mathrm{l} / \mathrm{min}$ and finally a submergible pump where the flow of 3 and $9 \mathrm{I} / \mathrm{min}$ was adjusted with a valve. The first two pumps were used during the first test session, while in the second one just the submergible pumps were used. In all the tests were simulated different urban water runoff conditions. Each well required two tanks that we were swapping from one test to the next one.

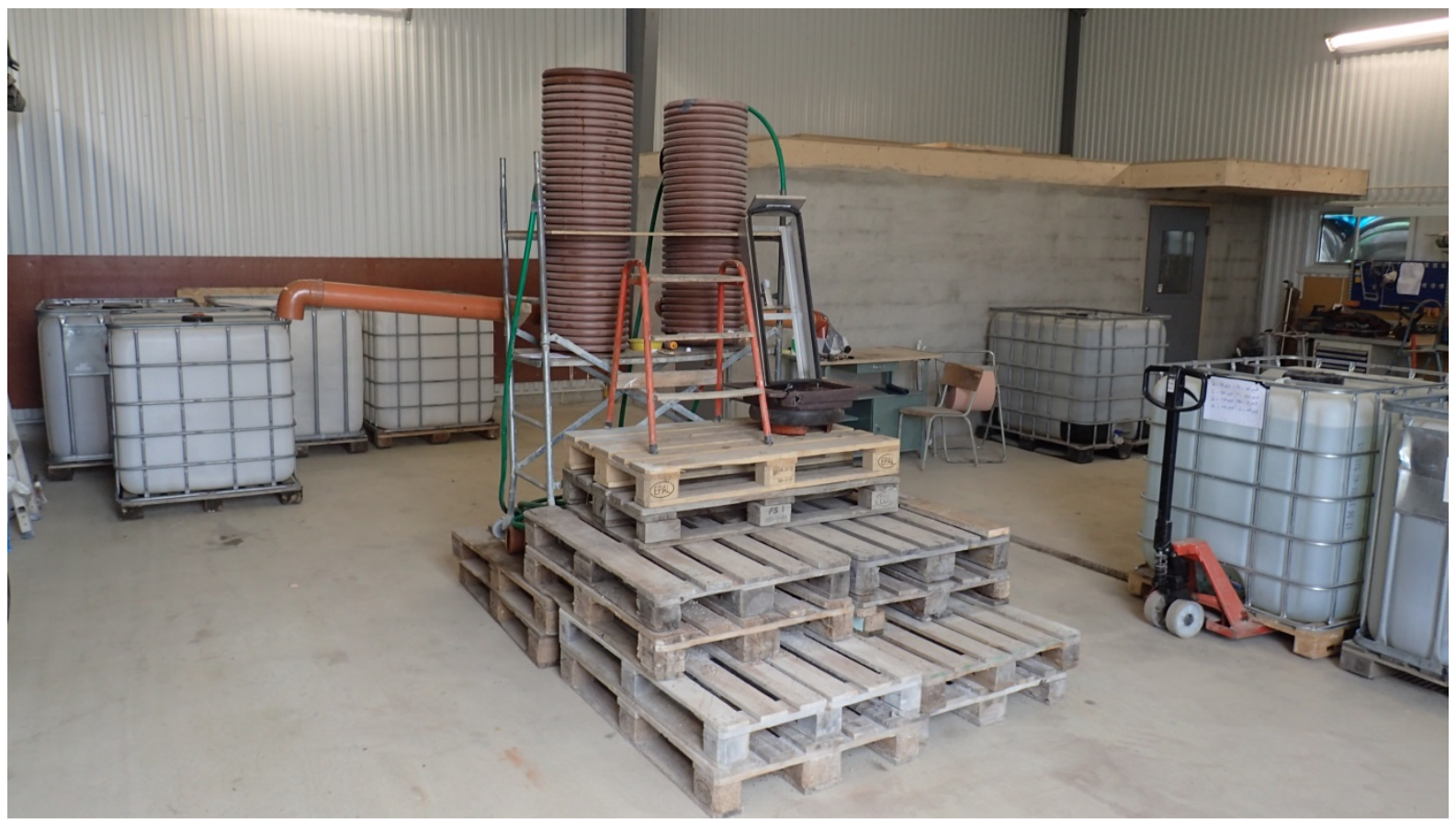

Fig. 13. Rent Dagvatten inside facilities in Flen. Simulation of the two wells

A common drainage catchment size is $400 \mathrm{~m}^{2}$, which according to the two different pumps used and the rational method for quantifying the stormwater runoff (3) the equivalent rain intensity can be computed. The rational coefficient is assumed to be 0.9 common for urban impervious areas.

$Q=C \cdot i \cdot A$

Where $Q$ is the runoff flow in $\mathrm{m}^{3} / \mathrm{h}, C$ is the coefficient without units, $i$ is the intensity in $\mathrm{mm} / \mathrm{h}$ and $A$ is the drainage catchment area in $\mathrm{m}^{2}$. In the following table can be seen the equivalent intensities (Table 9).

Table 9. Application of the rational method to compute the equivalent intensity

\begin{tabular}{|c|c|c|c|c|}
\hline $\begin{array}{c}\text { Q, runoff flow } \\
{[\mathbf{l} / \mathbf{m i n}]}\end{array}$ & $\begin{array}{c}\mathbf{Q}, \text { runoff flow } \\
{\left[\mathbf{m}^{3} / \mathbf{h}\right]}\end{array}$ & A, area $\left[\mathbf{m}^{2}\right]$ & C, coefficient & $\begin{array}{c}\text { leq, }_{\text {equivalent intensity }} \\
{[\mathrm{mm} / \mathrm{h}]}\end{array}$ \\
\hline 3 & 0.18 & 400 & 0.9 & 0.5 \\
\hline 9 & 0.54 & 400 & 0.9 & 1.5 \\
\hline 13 & 0.78 & 400 & 0.9 & 2.2 \\
\hline 60 & 3.6 & 400 & 0.9 & 10 \\
\hline
\end{tabular}

The test procedure was clear and can be summarize in the following points for the first session, without particles, after filling the tanks with 500 I of tap water.

- Add the amount of diluted heavy metals mixture $(500 \mathrm{ml})$ in the tank.

- Stir the mixture for five minutes with a motorized stirrer.

- Take samples before the test starts 
- Switch on the pump and run the test

- Stir the received water for five minutes again

- Take samples of the received water after the test has been run

- Re-add the amount of heavy metals mixture into the tank (500 ml)

Regarding the second session, the unique difference is that the stirring was kept during longer time on the simulation and $100 \mathrm{~g}$ of sediments were added at the same time as the heavy metals solution.

This basic layout was repeated ten times, and then the water was discarded to destruction. Before hand and assuming that a reduction of the $40 \%$ is achieved approximately in every run, at the tenth run the concentration should be around 2.5 times higher than the starting one before running the test (Table 4). The main reason to reuse the water was for sustainable reason. However, the destruction of contaminated water is not free of charge so it was also an economical motivation. Regarding the sediments, although the water was run ten times, sediments were just added on eight occasions, since the amount of sediments inside the tanks was already higher than common stormwater values.

The concentration of dissolved heavy metals has been analysed on the samples took during the first session. On the other hand, for the second session since sediments were used, 26 samples (13 tests) were selected to be analysed. The analysis of these samples required first a digestion to disintegrate the particles and obtain the total amount of dissolved heavy metals. Finally, the turbidity was tested for all the samples of the second session, but due to the precision of the equipment used the results might not be reliable below 21 NTU.

\subsubsection{Filter cassettes}

In the different tests run, mainly two cassettes were used. The first one is from FlexiClean $A B$ and the second one from Absorbenta Miljö $A B$. Further references will be known as $\boldsymbol{A}$ (FlexiClean) and $\boldsymbol{B}$ (Absorbenta) filter cassettes. In the following image both cassettes used can be seen (Fig. 14).
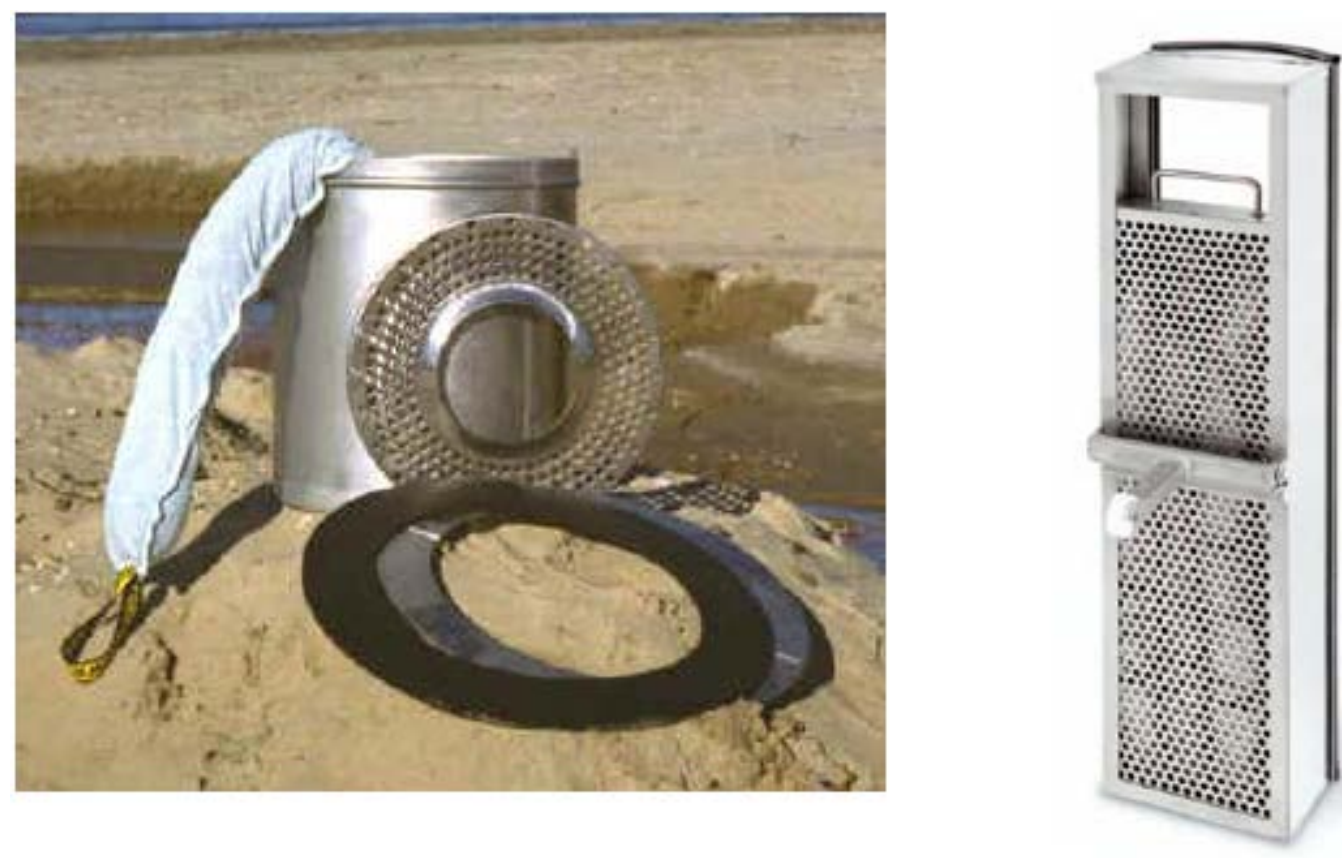

Fig. 14. Left: Absorbenta filter cassette [Source: www.absorbenta.se] / Right: FlexiClean filter cassette [Source: www.flexiclean.eu] 
In order to increase the retention time of the synthetic stormwater inside the filter material, two modified FlexiClean filter cassette were used in some of the tests. A thin metal plate covering $30 \mathrm{~cm}$ is used and also the sides were sealed with silver tape. Moreover, since some leaking from the sides was detected, another modification was applied, in this case extra foam was placed on the edges of the cassette to increase the pressure to the sides of the well and avoid leaking (Fig. 15). In further references will be known as $\boldsymbol{A} \mathbf{1}$ and $\boldsymbol{A} \mathbf{2}$, respectively.
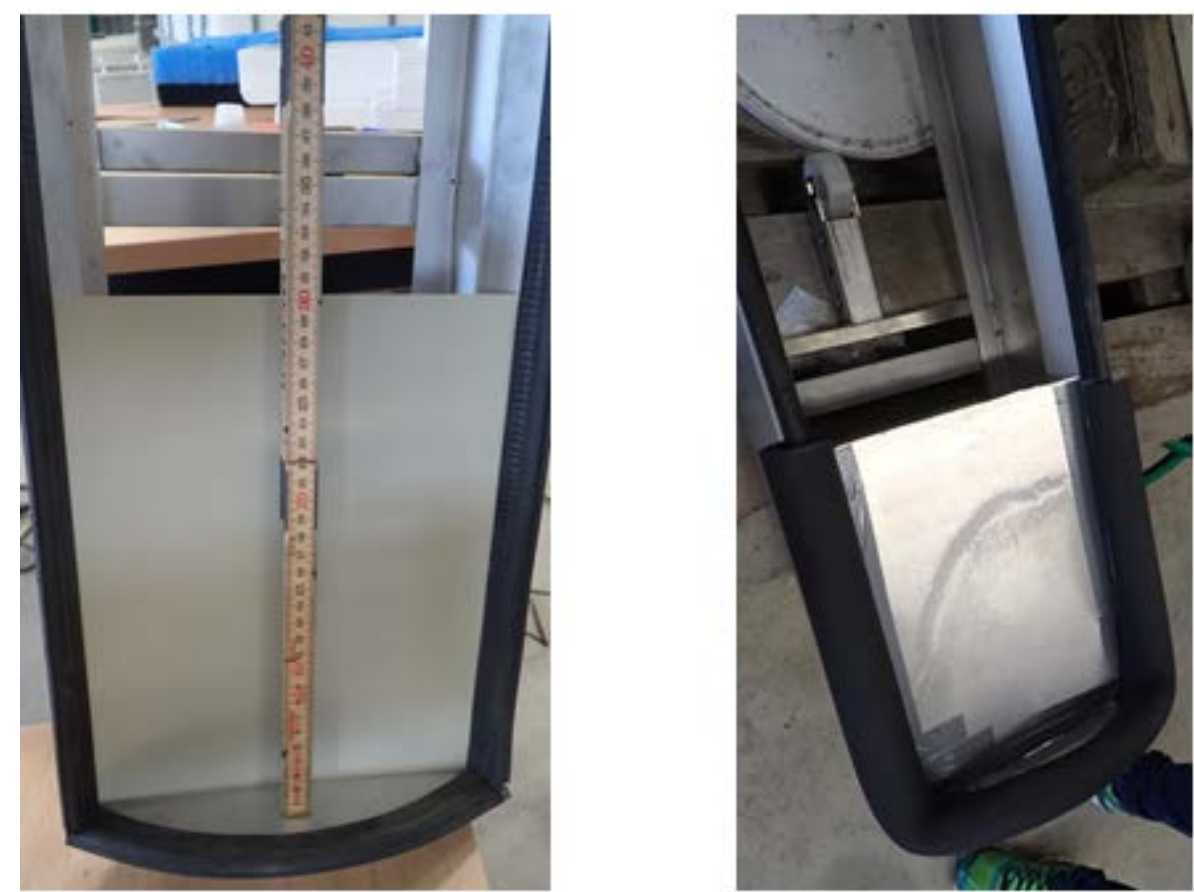

Fig. 15. Left: Modified FlexiClean filter cassette before sealing sides (A1) / Right: Second modification on the FlexiClean filter cassette (A2)

Finally, two of the tests were run with floating filters. These floating filters are provided by Acitex Miljöskydd $A B$. These filters are composed by a multiple layer of different materials (Fig. 16). In further references will the floating filters be known as $\boldsymbol{C}$.

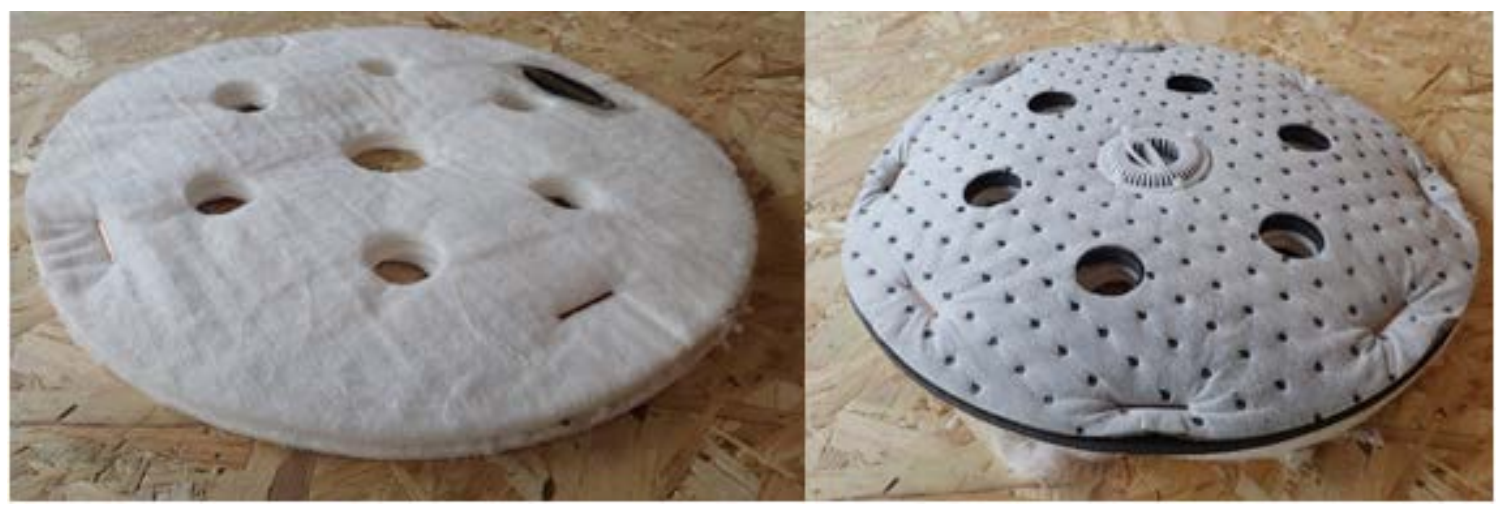

Fig. 16. Acitex Miljöskydd AB floating filters 
The number of tests runs in each type of filter and under which conditions the test was performed is described as a summary, in Table 10. Type A filters are ones more tested, since it is the easiest to maintain and change the filter material.

Table 10. Number of test in each type of filter cassettes and in which condition

\begin{tabular}{|c|l|c|c|c|c|c|}
\cline { 2 - 7 } \multicolumn{1}{c|}{} & Flow & A & B & A1 & C* & A2 \\
\hline \multirow{2}{*}{ First test session } & $13 \mathrm{l} / \mathrm{min}$ & 14 & 5 & - & - & - \\
\cline { 2 - 7 } & $60 \mathrm{I} / \mathrm{min}$ & 5 & - & 10 & 2 & - \\
\hline \multirow{2}{*}{ Second test session } & $9 \mathrm{I} / \mathrm{min}$ & - & - & 21 & - & - \\
\cline { 2 - 7 } & $3 \mathrm{I} / \mathrm{min}$ & - & 2 & 1 & - & 10 \\
\hline
\end{tabular}

* Floating filters

\subsection{Sample analysis}

From each field sample, $15 \mathrm{ml}$ were poured into a smaller recipient. Then the analysis of these samples was done by inductively coupled plasma-mass spectrometry (ThermoScientific ICAP Q) with a FAST injection system and using conventional operational setup. All the samples were analysed equally, but samples from the second tests session had to be digested first in order to convert all the particles into dissolved metals. 


\section{RESULTS}

\subsection{Rain events classification}

The amount of events for both stations is presented in Table 11, according to the classification methodology described in the previous chapter (3.1).

Table 11. Number of events, mean duration [h] and mean accumulated precipitation [ $\mathrm{mm}]$ from both stations

\begin{tabular}{|l|c|c|c|}
\hline Station & \# Events & Mean duration [h] & Mean accumulated precipitation [mm] \\
\hline Femman Huset & 275 & 4.51 & 4.12 \\
\hline Lejonet Skansen & 326 & 4.93 & 4.62 \\
\hline
\end{tabular}

The difference between the values of events, although it can be due to the movement of the storm over Gothenburg, cannot be considered to be the cause of that significant difference since both stations are fairly close. Therefore, it is due to the interrupted times of recording data. In the following plots it is represented the scatter plot of the different events, for the Lejonet Skansen station because a larger amount of events were recorded there (Fig. 17).

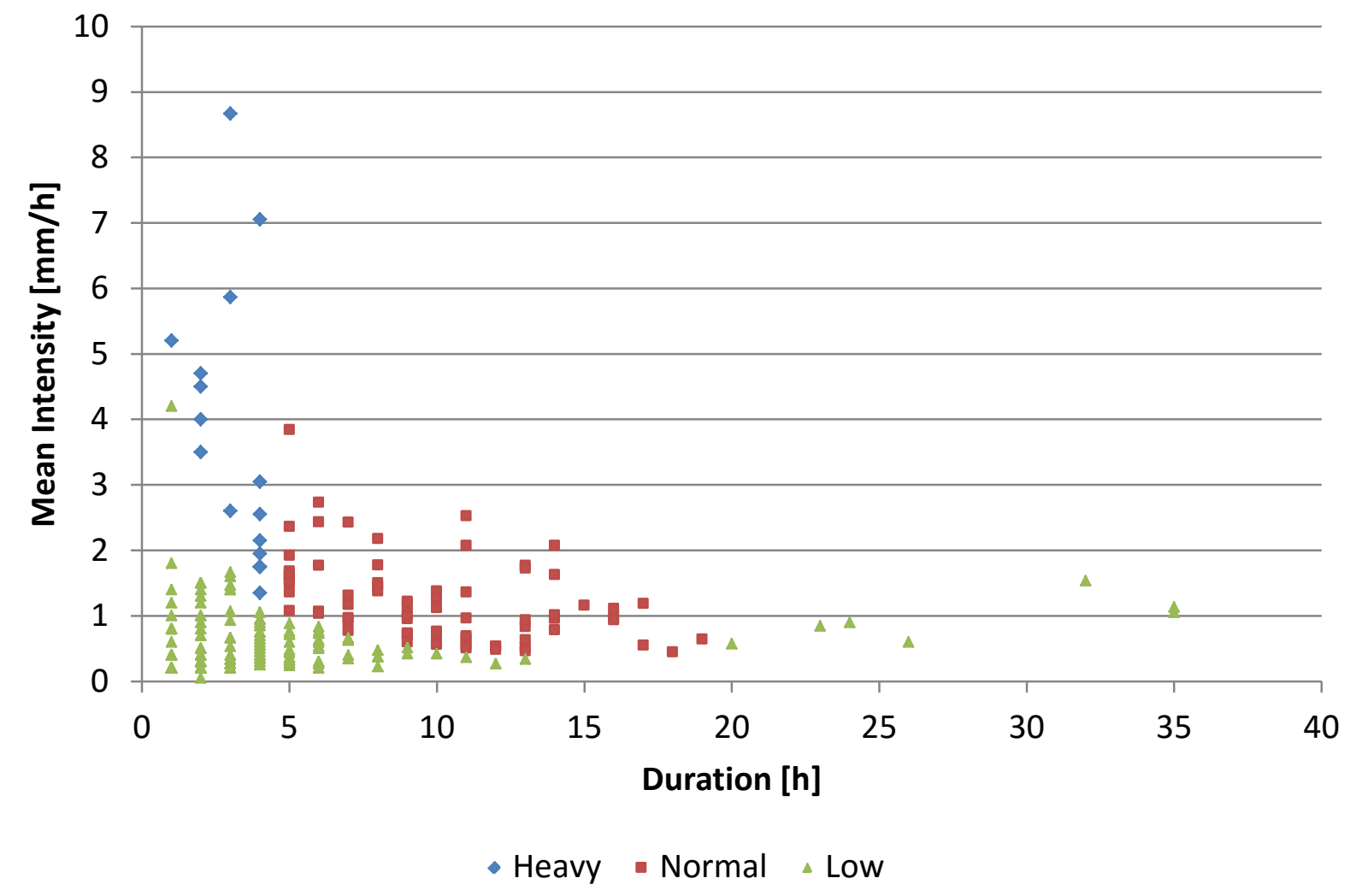

Fig. 17. Mean intensity and duration from the different events for the Lejonet Skansen station (Classified)

Another way to present the results from above is by a circular diagram. Where the amount of events of each type are itemised and also the percentage from the total of each is shown (Fig. 18). For the heavy type of rain, it represents a $5.2 \%$ of the total with 17 events in two years, then for the same period the normal type of rain covers $22.1 \%$ with 72 events. Finally, the low type of rain has the major part with 237 events which suppose a $72.7 \%$ of the total. 


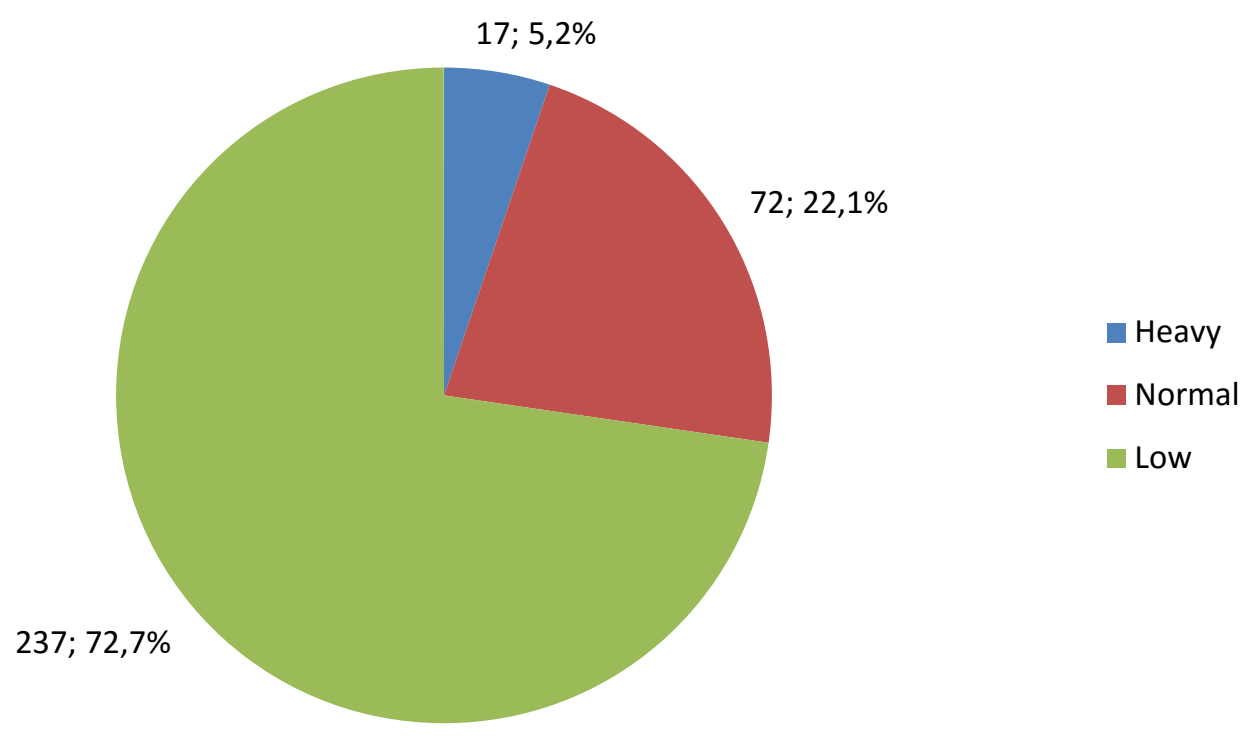

Fig. 18. Number of events of each type and percentage from the total amount

Finally, all three types of rains have a range of intensities. In the following table (Table 12) and figure (Fig. 19) these values are presented and plotted for a further visual interpretation.

Table 12. Mean, maximum and minimum intensity values for the three types and two stations

\begin{tabular}{|c|c|c|c|}
\hline Femman huset & Mean Intensity $[\mathrm{mm} / \mathrm{h}]$ & Max. Intensity $[\mathrm{mm} / \mathrm{h}]$ & Min. Intensity $[\mathrm{mm} / \mathrm{h}]$ \\
\hline Heavy & 3.7 & 8.5 & 1.2 \\
\hline Normal & 1.1 & 2.6 & 0.4 \\
\hline Low & 0.5 & 1.6 & 0.2 \\
\hline Lejonet Skansen & Mean Intensity $[\mathrm{mm} / \mathrm{h}]$ & Max. Intensity $[\mathrm{mm} / \mathrm{h}]$ & Min. Intensity $[\mathrm{mm} / \mathrm{h}]$ \\
\hline Heavy & 3.7 & 8.7 & 1.4 \\
\hline Normal & 1.2 & 2.7 & 0.4 \\
\hline Low & 0.5 & 1.8 & 0.1 \\
\hline
\end{tabular}

However, in the table there are the results from both stations, while in the following figure there are just represented the values from the Lejonet Skansen station.

Once the different rain events are classified, it can be seen that the equivalent intensities achieved by the different pumps belong to heavy rain event $(10 \mathrm{~mm} / \mathrm{h}$ for the $60 \mathrm{l} / \mathrm{min}$ pump), high normal rain event $(2.2 \mathrm{~mm} / \mathrm{h}$ for the $13 \mathrm{l} / \mathrm{min}$ pump), mean normal rain event $(1.5 \mathrm{~mm} / \mathrm{h}$ for $9 \mathrm{l} / \mathrm{min})$ and mean low rai event $(0.5 \mathrm{~mm} / \mathrm{h}$ for $3 \mathrm{l} / \mathrm{min}$ ) (Table 9$)$. 

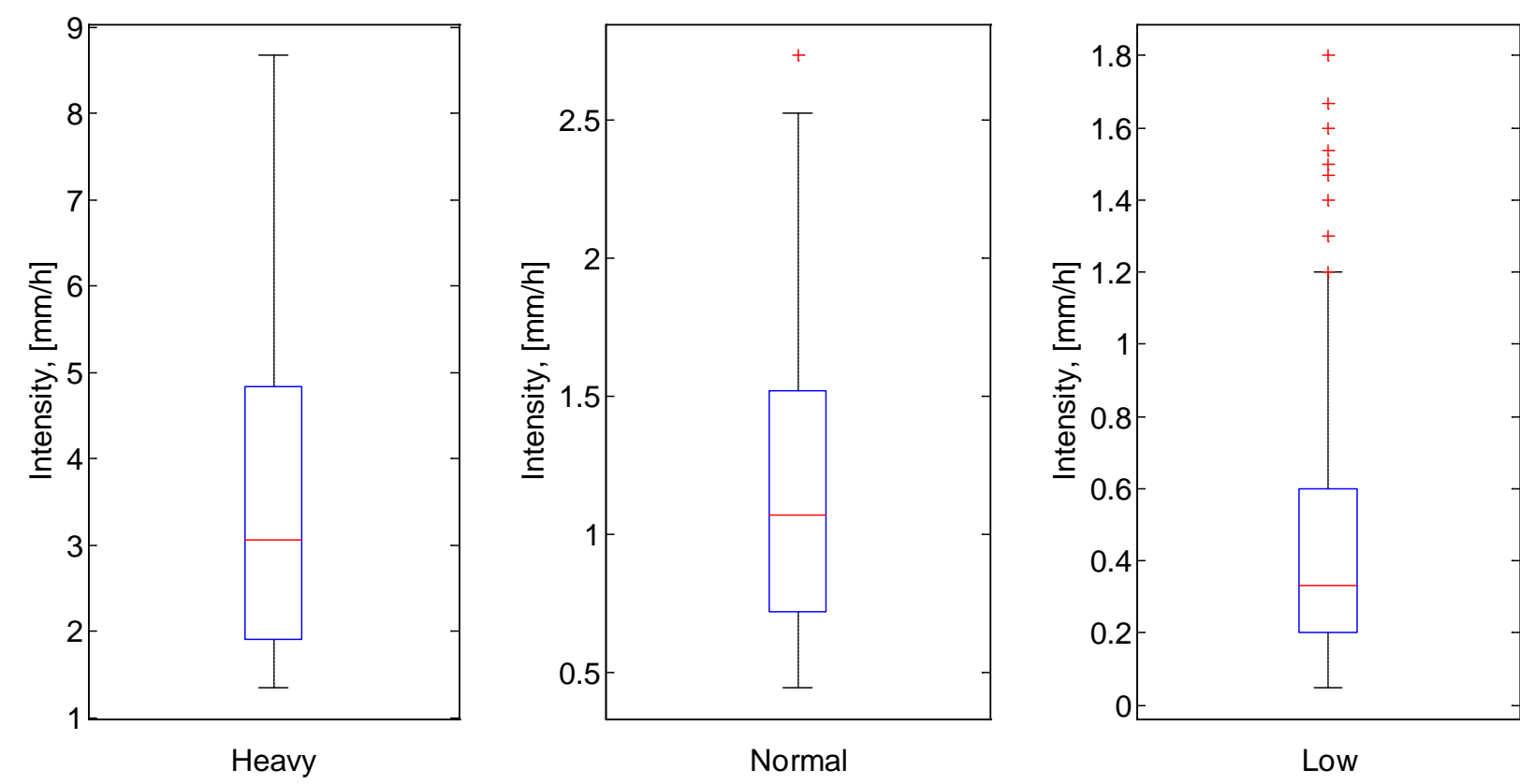

Fig. 19. Average, minimum and maximum of intensity ranges of each type of storm

\subsection{First test session}

The different samples taken during the first 36 tests were analysed in Chalmers WET laboratory. In these tests no particles were used, just dissolved heavy metal salts, therefore it can be assumed that under this conditions the tests represent the toughest situation feasible. In the following table it is described the content of the different tests and in which filter cassette and condition was tested (Table 13).

Table 13. Description of the filter material content tested and test number

\begin{tabular}{|l|c|c|c|c|}
\hline Filter material & A (13 I / min) & A (60 I/min) & B (13 I/min) & A1 (60 I/min) \\
\hline Bark & 1 & 13 & 12 & 22 \\
\hline PUF, coarse and medium & 2 & - & - & 33 \\
\hline PUF, fine and AC & 3 & - & - & 24 \\
\hline PUF, medium and AC & 4 & 20 & - & - \\
\hline PUF, coarse and AC & 6 & - & - & 32 \\
\hline PUF, all foams & 11 & - & - & - \\
\hline Air blown PPE & 5 & - & - & 31 \\
\hline Recycled PU granulate & 7 & - & 29 & 28 \\
\hline Recycled PU powder & 19 & - & & - \\
\hline Bark/Chitosan & 8 & - & 21 & - \\
\hline Bark/Chitosan just sprayed & 10 & - & - & - \\
\hline GFH and Recycled PU granulate & 14 & 17 & - & - \\
\hline Coarse PUF and NC & 9 & - & - & 34 \\
\hline Coarse PUF, NC and Acitex & 18 & - & - & - \\
\hline GFH & - & 16 & - & - \\
\hline Air blown PPE and AC PUF & - & 15 & - & - \\
\hline Bark and GFH & - & - & 23 & 25 \\
\hline Bark and Recycled PU granulate & - & - & 27 & 26 \\
\hline Bark and AC PUF & - & - & - & 30 \\
\hline
\end{tabular}


Apart from the previous filter materials, the two floating filters were also tested. In general, the performance achieved was not substantially relevant. In a high number of cases the reduction between pre and post running the tests is either null or negative, independently of the filter cassette used. However, for some heavy metals, in specific tests, positive uptake percentages have been achieved, with the maximums as it is described in the next table (Table 14).

Table 14. Maximum uptake percentage achieved in each heavy metal and test number

\begin{tabular}{|l|c|c|c|c|c|c|}
\hline Heavy metals & $\mathbf{P b}$ & $\mathbf{C u}$ & $\mathbf{Z n}$ & $\mathbf{N i}$ & $\mathbf{C d}$ & $\mathbf{C r}$ \\
\hline Max \% uptake & $84.4 \%$ & $45.3 \%$ & $14.2 \%$ & $18.6 \%$ & $14.6 \%$ & $79.3 \%$ \\
\hline Test number & 20 & 17 & 27 & 31 & 15 & 23 \\
\hline
\end{tabular}

In the following figure (Fig. 20), it is shown the performance achieved for the different filter cassettes and conditions with pine bark as filter material. It is clear that a high variability is registered on the percentage uptake. Moreover, it is important to highlight that mostly the A filter cassette with the two flow conditions register positive uptakes, although the others two do not present that good values this might be related to other issues such as detection errors or leaching of metals from the filter material than a bad performance itself.

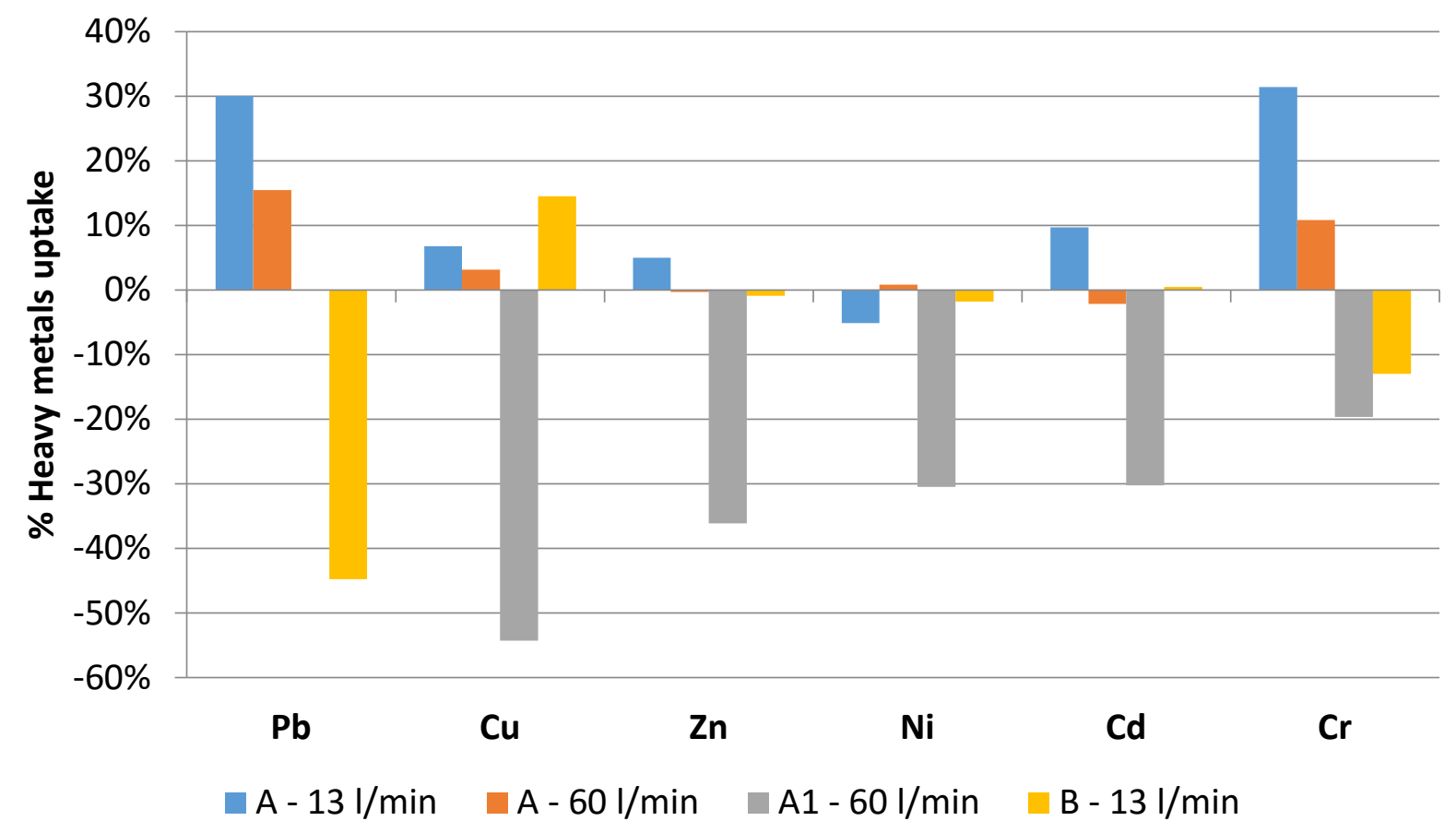

Fig. 20. Retention percentage of each metal with pine bark and all the cassettes, tests \#1, \#13, \#22 and \#12

Regarding the flow conditions, it can be seen in the previous figure that with higher flow the uptake achieved is reduced. This phenomenon occurred not just between the A cassette against the two types of flows. It was also noticed between the A and A1 cassettes as it can be seen in the following figure (Fig. 21). 


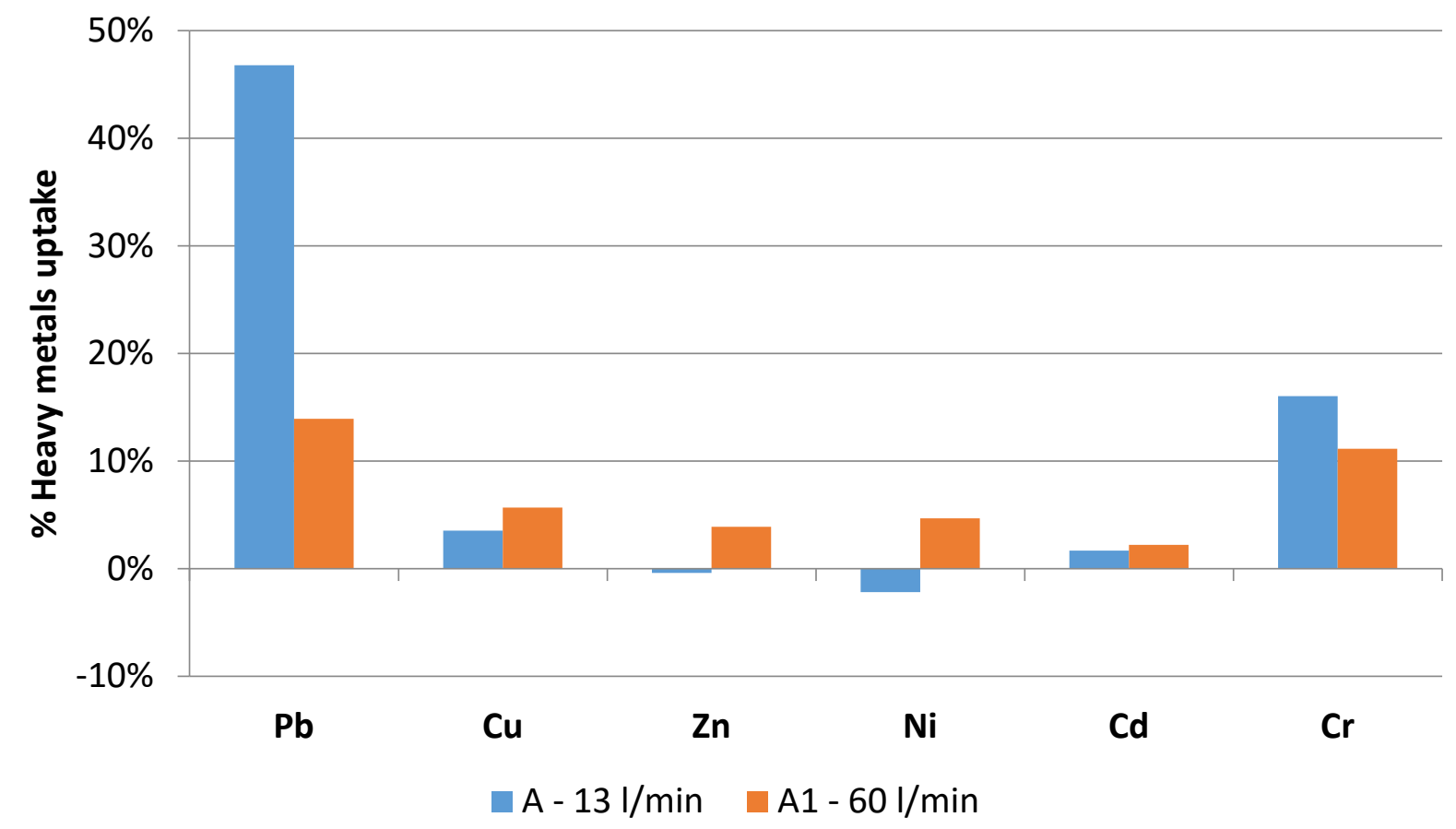

Fig. 21. Retention percentage with medium and coarse PUF, tests \#2, \#33

Among all the tests run, the filter material that registered the best performance was the combination of pine bark and chitosan both as material and sprayed under the low flow conditions with the A filter cassette (Fig. 22).

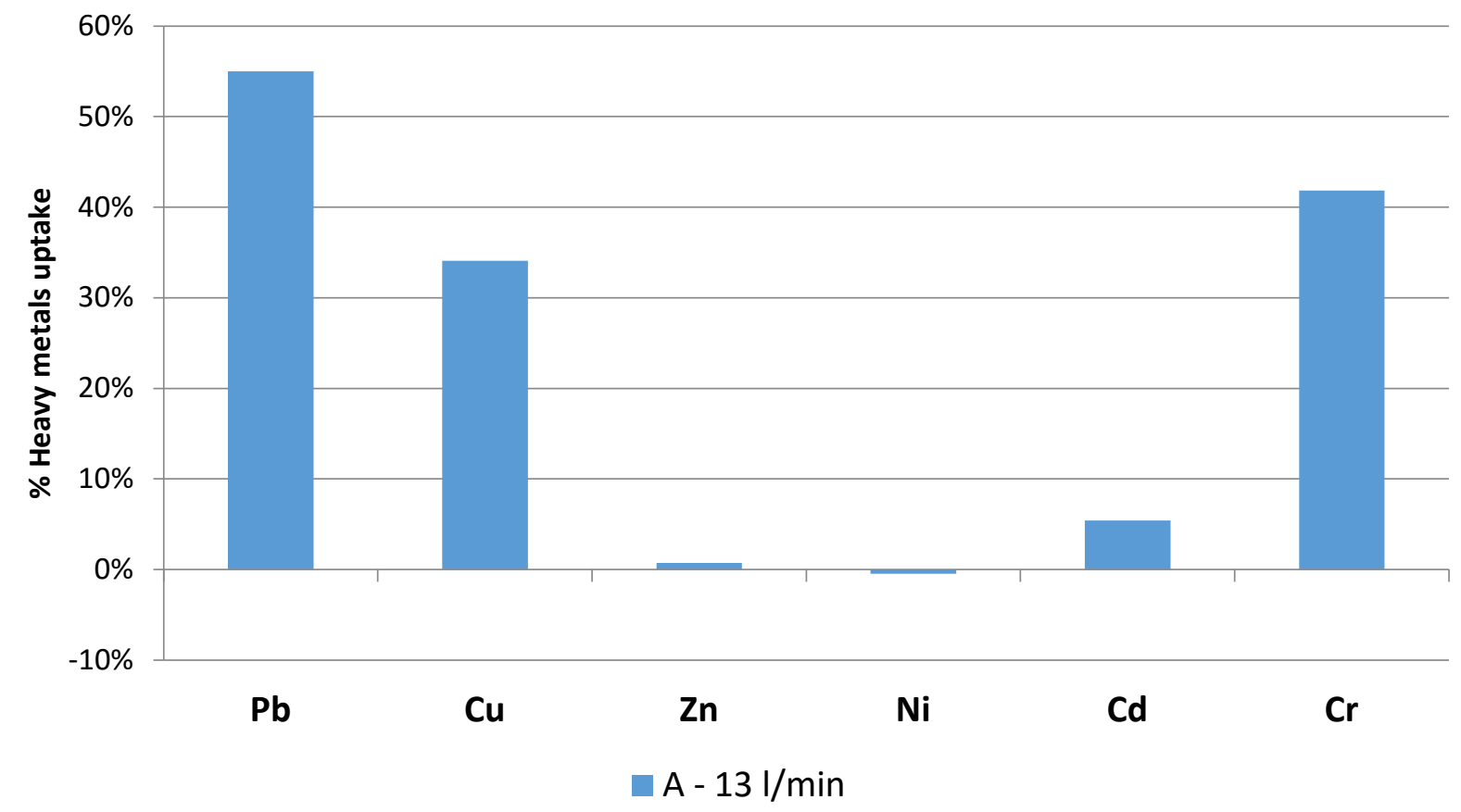

Fig. 22. Retention percentage by pine bark and chitosan, test \#8

In the Appendix, there is described in a detailed way the percentage uptake for each heavy metal and each test run. 


\subsection{Second test session}

During the second session a total of 34 tests were run. In the following table the different filter materials and the conditions under which conditions the tests were done are described (Table 15). Moreover, the tests selected for analysis are highlighted in the table.

Table 15. Description of the filter material content tested and test number.

\begin{tabular}{|l|c|c|c|c|}
\hline Filter material & A1 - 9 I/min & A1 - 3 I/min & A2 - 3 I/min & B - 3 I/min \\
\hline Pine Bark & 1,12 & 22 & 29 & 30 \\
\hline PUF, Coarse & 2 & - & - & - \\
\hline PUF, Medium & 3 & - & - & - \\
\hline PUF, Fine & 4 & - & - & - \\
\hline AC PUF & 5 & - & - & - \\
\hline Recycled PU granulate & 6 & - & - & - \\
\hline Bark and Clay & 7 & - & 23 & - \\
\hline Recycled PU powder & 8 & - & - & - \\
\hline Peat & 9 & - & 24 & - \\
\hline Bark and Pumice & 10 & - & 25 & - \\
\hline Air blown PPE & 11 & - & - & - \\
\hline GFH and Recycled PU granulate & 13 & - & - & - \\
\hline Bark and GFH & 14 & - & - & - \\
\hline Bark and Recycled PU granulate & 15 & - & - & - \\
\hline Bark and Peat & 16 & - & 26 & - \\
\hline Bark, Peat and Clay & 17 & - & 27 & - \\
\hline Air blown PPE and AC PUF & 18 & - & - & - \\
\hline Bark and Recycled PU powder & 19 & - & - & - \\
\hline Peat and Pumice & 20 & - & - & - \\
\hline Absol and Peat & 21 & - & 28 & - \\
\hline Bark and Chitosan & - & - & 31 & 32 \\
\hline Peat and Chitosan & - & - & 33 & - \\
\hline GFH, Recycled PU granulate and Chitosan & - & - & 34 & - \\
\hline
\end{tabular}

In the following table, the maximum uptakes achieve in every element are shown. Although in some cases the percentage is slightly less, for zinc, nickel and cadmium specifically the values are higher (Table 16). However, it is important to notice that in this case these maximum levels are obtained in two of the tests.

Table 16. Maximum uptake percentage achieved in each heavy metal and test number

\begin{tabular}{|l|c|c|c|c|c|c|}
\hline Heavy metals & $\mathbf{P b}$ & $\mathbf{C u}$ & $\mathbf{Z n}$ & $\mathbf{N i}$ & $\mathbf{C d}$ & $\mathbf{C r}$ \\
\hline Max \% uptake & $82 \%$ & $40 \%$ & $20 \%$ & $20 \%$ & $21 \%$ & $62 \%$ \\
\hline Test number & 24 & 24 & 31 & 31 & 31 & 24 \\
\hline
\end{tabular}

It can be seen in the following figure the positive effect on the percentage of heavy metal uptake achieved by increasing the contact time with the same filter material (Fig. 23), in this cases pine bark and peat. The contact time increases due to the flow reduction, which $3 \mathrm{l} / \mathrm{min}$ supposes more than the $70 \%$ of the rain events and by ensuring that the leakage from the sides is the minimum possible. 


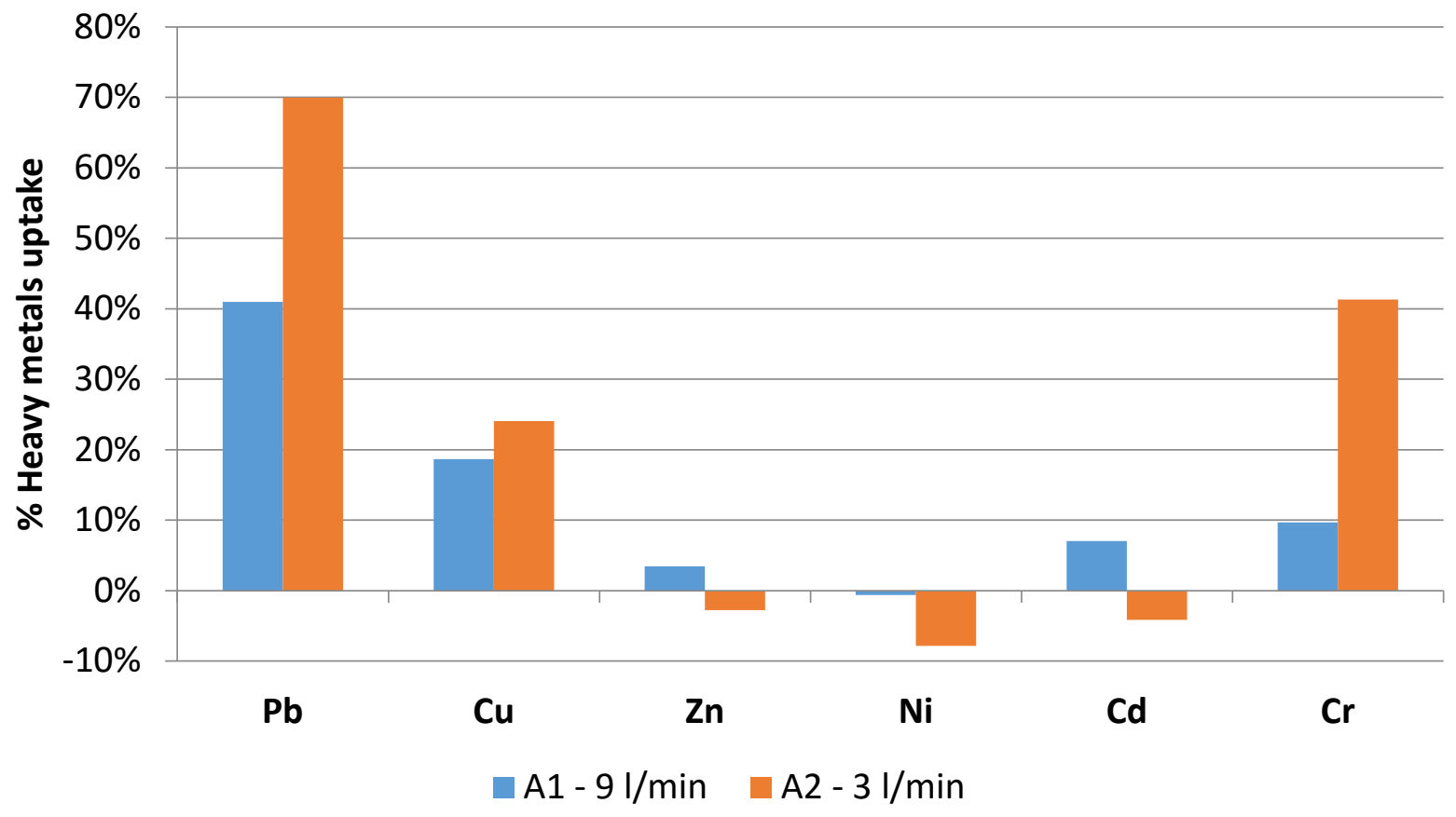

Fig. 23. Retention percentage by pine bark and peat, tests \#16 and \#26

The positive effect of a bigger contact time can be seen in the following figure. Moreover, the major uptake on lead, copper and chromium has been achieved with peat as filter material, the double modified filter cassette and mean flow according to the low rain event (Fig. 24). Regarding zinc, nickel and cadmium the uptake is significantly lower, around $10 \%$.

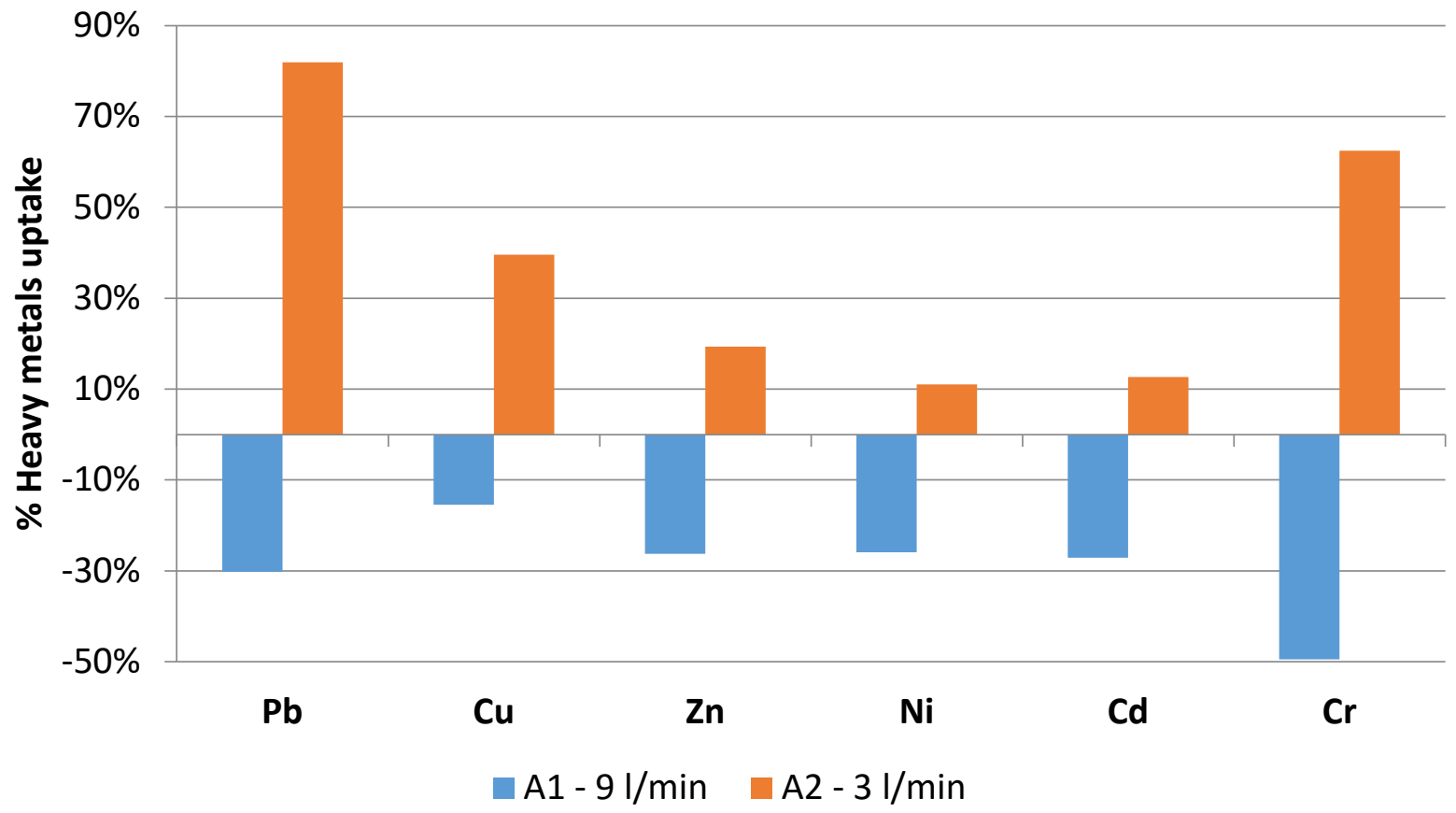

Fig. 24. Retention percentage by peat, tests \#9 and \#24

A comparison between the filter material pine bark and chitosan used in the first session and the second session with different cassettes and flow regimes is shown in the following figure (Fig. 25). The bigger contact time leads to a major uptake, especially on zinc, nickel and cadmium, while the 
copper removal stays in range, lead and chromium varies significantly but this might be related to the detection precision of the equipment due to the concentrations are low. Between $A 2$ and $B$ in the second session, the difference on the percentage uptake it is directly related to the particles retention. This can be seen in the following figure (Fig. 26), where the filter cassette type A promotes major particle retention than the type B filter cassette.

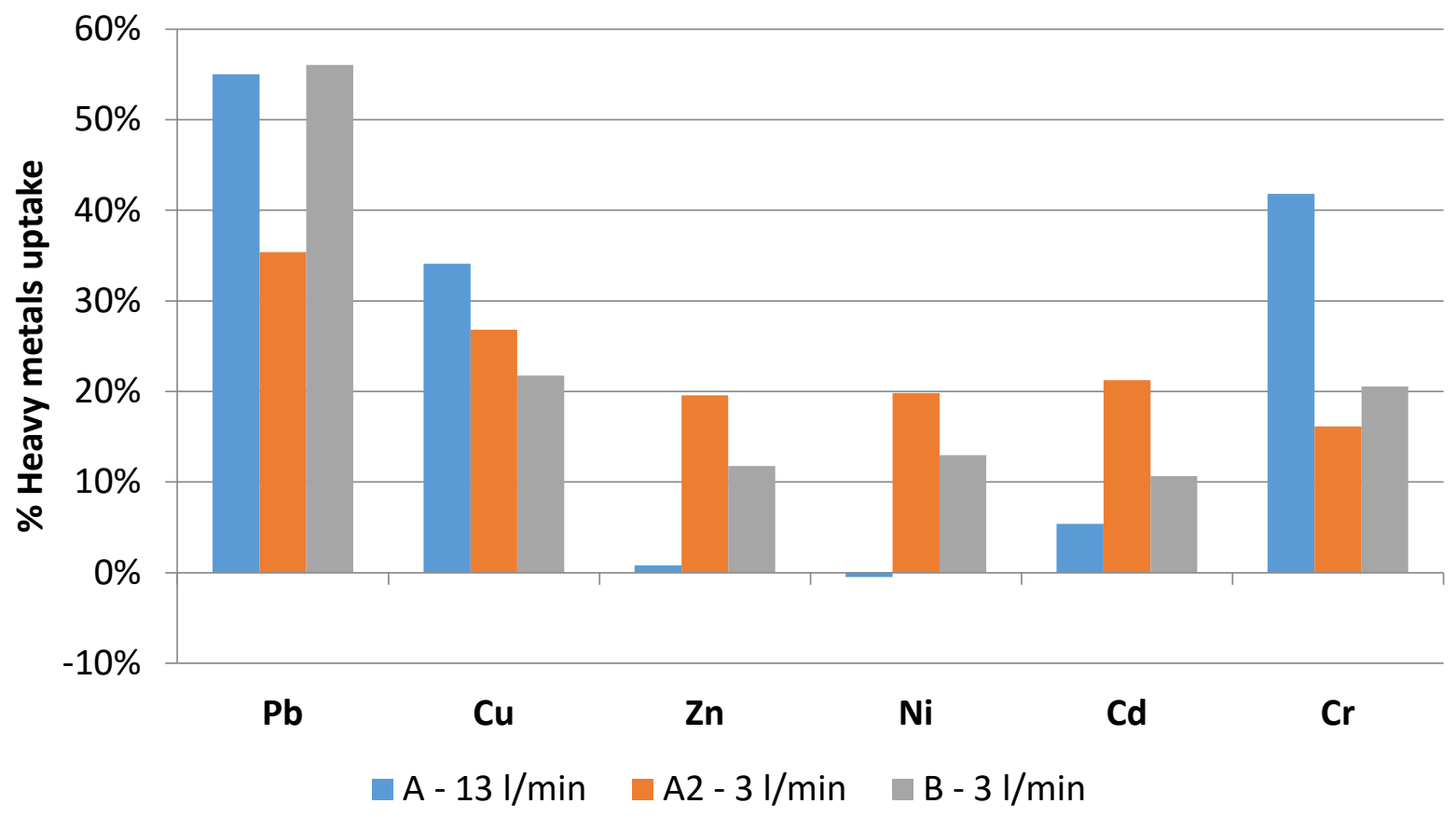

Fig. 25. Retention percentage by pine bark and chitosan, tests \#8 (first test session), \#31 and \#32

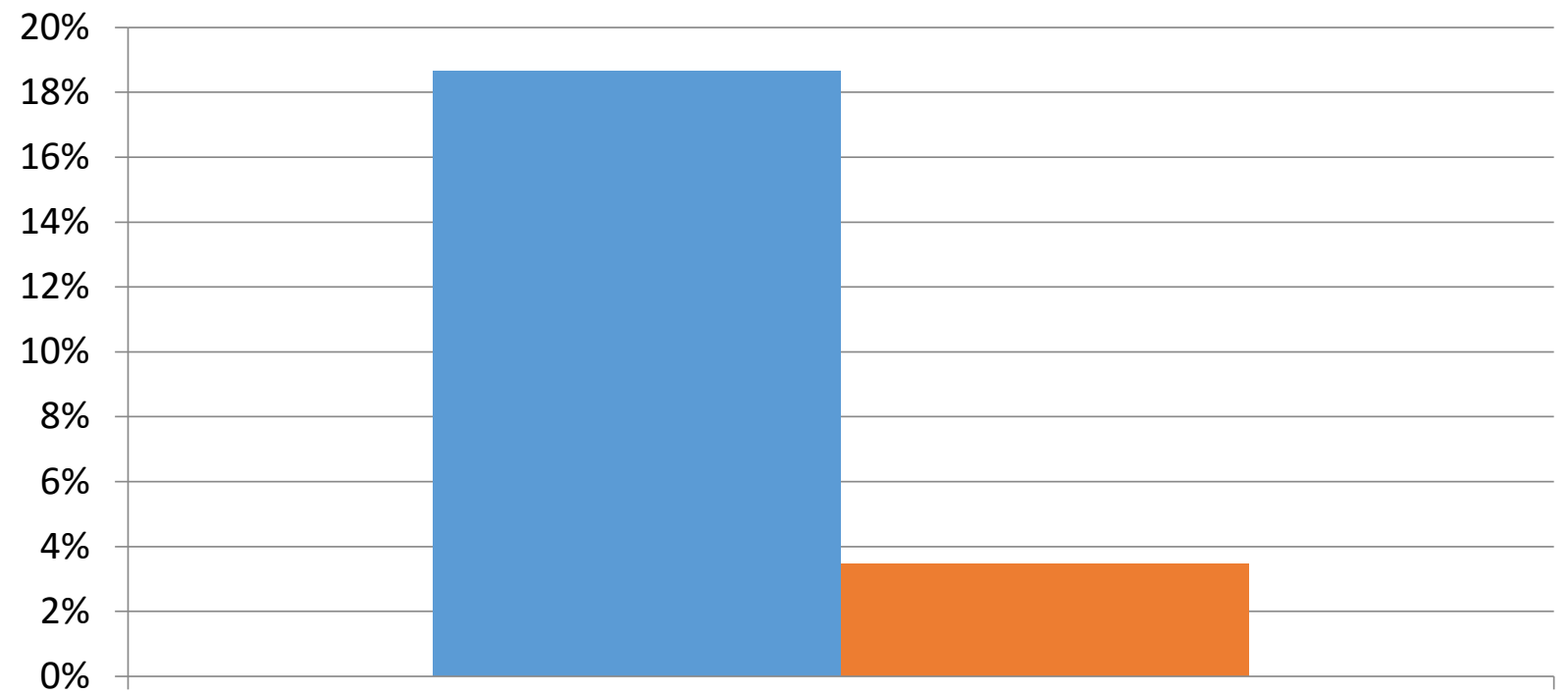

\section{Turbidity reduction}

\#31 \#32

Fig. 26. Particles retention by means of turbidity reduction

In the Appendix, there is described in a detailed way the percentage uptake for each heavy metal on those tests that have been analysed. 


\section{DISCUSSIONS}

The storm events classification established is not unique, but provides an idea of how the different storm events are distributed over the Gothenburg area. Data from only two years were used and that might not be sufficient to evaluate the different types of rain episodes since they depend on a series of highly variable parameters all over the years. However, the classification provides a quantitative vision of how the different storm events are distributed on a yearly basis, where more than $70 \%$ of the events are considered of low intensity and only $5 \%$ might belong to extremely high intensity episodes. It is important to mention, that snow precipitation and melting has not been considered in the classification because input from the melting process occurs over time. The runoff flow achieved is in the same order of magnitude as the one obtained during low or normal rain event.

The selection of filter materials has not been restricted to just water treatment materials but also other types of materials have been analysed. Therefore, it has been difficult in some of them to finds references in the literature. However, a better performance was achieved with those that have been used previously in similar applications according to the results obtained.

In first test session only dissolved metal were used and this was therefore the toughest tests that the filter materials had to cope with. The potential uptake according to the literature is achieved over several hours up to days of contact time, but in the simulation the retention time is in the order of minutes. This explains the almost zero metal retention for copper, nickel and zinc. However, for lead, cadmium and chromium the percentage of uptake can reach reasonable high levels on both positive and negative side, but this might not be related to the efficiency of the filter material per se. The causes behind this phenomenon can be due to measurement errors and the presence of some leaching of metals from the filter material, especially considering the low concentrations.

From an environmental point of view, a proper removal would be to retain both particles and dissolved forms. The filter materials remove heavy metals by means of retaining particles. The retention of metals in dissolved forms is practically inexistent since it is highly dependent on the contact time. Since it is low, the adsorption and ion exchange between the filter material and the synthetic stormwater is limited, therefore just physical filtration of particles is achieved. However, it is important to consider that in general the dissolved fraction contains the major toxicity, so from an environmental point of view should be the target fraction.

In second test session, where the flow regime was reduced to increase the contact time and some particles were added to the test solution. In these cases higher removal rates were achieved on lead, copper and chromium, but as mentioned before the magnitude order of these metal systems are lower in comparison to the other three. Moreover, during the second test session, uptake percentages between $15-20 \%$ on zinc, nickel and cadmium were achieved with two types of materials. This percentage, although it is lower in comparison with the other three metals, is more reliable since the detection errors in these metal systems are smaller due to higher concentrations. In addition, metal leaching from the test materials is expected to be less significant. Moreover, the flow regimes used during the second tests session covers the $95 \%$ of the rain events over Gothenburg and therefore the results obtained are more reliable for a year basis rain pattern. It is important to consider that the retention percentages obtained from the literature reviewed cannot be compared with the ones obtained on the simulations, since the tests conditions are not the same.

Another important consideration is regarding the sediments used. Since particles were picked up during a maintenance session from already placed filters, although all particles sizes will be 
represented, the size distribution would be well classified with a predominant part of particles slightly large. By using well graded sediments with no predominant particle size, the obtained results might differ and retention might be lower. Moreover, the particles used, due to the contact with already contaminated water, had previously attached metal ions on their surface avoiding further adsorption that could happen during the mixing steps so the soluble part was increasing. In real life simulation, by removing particles, the uptake percentage expected might even be higher than the obtained in the different tests.

The overall simulation represents the reality with high fidelity, by using valves the flow regime can be adjusted at desired levels, common in reality. The contact time between stormwater and the filter material is in the same order on both reality and simulation. However, in reality sometimes the contact time might be even less or inexistent, between stormwater runoff and filter material, due to the lack of maintenance of gully pots that could produce a direct overflow to the network system over the filter material. The following focus should be put on being able to activate the filter materials, so the required time to achieve the maximum potential uptake was reached under simulation contact times range.

The best materials are bark with chitosan and peat due to the low contact time that require, especially for peat. However, chitosan and peat are also dependant on their own condition of deacetylation and degradation. Therefore, under small variances the uptake percentage might indeed be higher. Finally, these materials can be improved in order to activate the adsorption sites to achieve a faster ion exchange, under this condition a comparison between the difference uptake achieved and the confection costs would be a decisive parameter.

It can be concluded from the turbidity results that filter cassettes type $A$ enhanced a major particle removal than $B$ type. However, this result is not conclusive since the amount of tests run under the $B$ type configuration are much lower, so in order to be able to confirm this statement additional tests should be run under this configuration. 


\section{CONCLUSIONS AND RECOMMENDATIONS}

In urban environments due to the different human activities, the existent pollution is deposited and is further wash-off during rain events. The stormwater runoff in urban environments contains particles, dissolved heavy metals, nutrients and organic matter, which represent a potential threat from the environmental point of view for the receiving water bodies. Therefore, in order to preserve the quality and biodiversity of these environments, polluted stormwater from non-point sources has to be treated before is released.

A set of potential filter materials have been tested in this study in order to address the treatment procedure of stormwater through filtration. Filter materials have been tested by running a simulation of high fidelity to the reality under the different storm situations that can be encountered in the Gothenburg area. By evaluating the rain data from the city the different runoff flow rates, according to the rain intensities, have been determined.

A bigger rain database will provide an accurate classification, although not extremely changes would be expected from the actual one. The filter materials act mostly as physical removal media since the retention time is not long enough to enhance the maximum potential ion exchange. Furthermore, the simulation is close to real life situation, but in some aspects, such as the sediments used, some uncertainties were introduced on it. The idea showed interesting results but it has to be improved in order to increase the retention achieved on the dissolved heavy metals part and reach uptake values closer to the ones seen in the literature. The best material used was the combination of pine bark with chitosan due to register uptake values over $20 \%$ in all of the metal systems. Moreover, not enough tests with configuration $B$ were run in order to confirm that configuration A performs better from the particle retention point of view.

As recommendations, future studies on how filter materials can be activated for a faster adsorption without losing the "low-cost" property, especially on the ones that have performed better. Moreover, some research on the maintenance operations, since there is not a clear opinion from the cassette suppliers on how frequent the filter materials have to be changed. Finally, it would be interesting to introduce strict legislation to the municipalities to force the maintenance of the gully pots since the filters sometimes are totally covered by sediments and cannot work properly then. 


\section{REFERENCES}

Ahlman, S., 2006. Modelling of Substance Flows in Urban Drainage Systems. Göteborg: Chalmers Reproservice.

Al-Asheh, S. \& Duvnjak, Z., 1997. Sorption of cadmium and other heavy metals by pine bark. Journal of Hazardous Materials, Volum 56, pp. 35-51.

Alemayehu, E. \& Lennartz, B., 2010. Adsorptive removal of nickel from water using volcanic rocks. Applied Geochemistry, 25(10), p. 1596-1602.

Bailey, S. E., Olin, T. J., Bricka, R. M. \& Adrian, D. D., 1999. A REVIEW OF POTENTIALLY LOW-COST SORBENTS FOR HEAVY METALS. Water Research, 33(11), pp. 2469-2479.

Bertrand-Krajewski, J.-L., Chebbo, G. \& Saget, A., 1998. DISTRIBUTION OF POLLUTANT MASS VS VOLUME IN STORMWATER DISCHARGES AND THE FIRST FLUSH PHENOMENON. Water Research, 32(8), pp. 2341-2356.

Björklund, K., 2011. Sources and Fluxes of Organic Contaminants. Gothenburg: Chalmers Reproservice.

Borris, M., 2013. Influential Factors in Simulations of Future Urban Stormwater Quality. Luleå: Universitetstryckeriet, Luleå.

Cettner, A., Ashley, R., Viklander, M. \& Nilsson, K., 2013. Stormwater management and urban planning: Lessons from 40 years of innovation. Journal of Environmental Planning and Management, 56(6), pp. 786-801.

Cheng, Z., Xu, Q. \& Gao, Y., 2013. Research Progress in Nano-Cellulose Modification. Advanced Materials Research, Volum 627, pp. 859-863.

Davis, A. P., Shokouhian, M. \& Ni, S., 2001. Loading estimates of lead, copper, cadmium, and zinc in urban runoff from specific sources. Chemosphere, Volum 44, pp. 997-1009.

Deletic, A., 1998. THE FIRST FLUSH LOAD OF URBAN SURFACE RUNOFF. Water Research, 32(8), pp. 2462-2470.

Eriksson, E. et al., 2007. Selected stormwater priority pollutants - a European perspective. Science of the Total Environment, Volum 383, pp. 41-51.

Etutu Ngoh, F., 2006. Heavy Metals Adsorption by Fiber Ash. Göteborg: Department of Civil and Environmental Engineering.

Freni, G., Mannina, G. \& Viviani, G., 2010. Urban storm-water quality management: centralized versus source control. Journal of Water Resources Planning and anagement, 136(2), pp. 268-278.

Genç-Fuhrman, H., Mikkelsen, P. S. \& Ledin, A., 2007. Simultaneous removal of As, Cd, Cr, Cu, $\mathrm{Ni}$ and Zn from stormwater: Experimental comparison of 11 different sorbents. Water Research, Volum 41, p. $591-602$.

Genç-Fuhrman, H., Wu, P., Zhou, Y. \& Ledin, A., 2008. Removal of As, Cd, Cr, Cu, Ni and Zn from polluted water using an iron based sorbent. Desalination, Volum 226, p. 357-370.

German, J., 2001. Stormwater sediments, removal and characteristics. Göteborg: Chalmers Reproservice. 
German, J., 2003. Reducing Stormwater Pollution - Performance of Retention Ponds and Street Sweeping. Göteborg: Chalmers Reproservice.

Göbel, P., Dierkes, C. \& Coldewey, W. G., 2007. Storm water runoff concentration matrix for urban areas. Journal of Contaminant Hydrology, Volum 91, pp. 26-42.

Huff, F. A., 1967. Time Distribution Rainall in Heavy Storms. WATER RESOURCES RESEARCH, pp. 1007-1019.

Hugron, S., Bussières, J. \& Rochefort, L., 2013. Tree plantations within the context of ecological restoration of peatlands: practical guide. Laval, Québec, Canada: Peatland Ecology Research Group (PERG).

Jha, I. N., lyengar, L. \& Prabhakara Rao, A. V. S., 1988. REMOVAL OF CADMIUM USING CHITOSAN. Journal of Environmental Engineering, Volum 114, pp. 962-974.

Kalmykova, Y., Strömvall, A.-M. \& Steenari, B.-M., 2008. Adsorption of $\mathrm{Cd}, \mathrm{Cu}, \mathrm{Ni}, \mathrm{Pb}$ and $\mathrm{Zn}$ on Sphagnum peat from solutions with low metal concentrations. Journal of Hazardous Materials, 152(2), p. 885-891.

Kalmykova, Y., Strömvall, A.-M. \& Steenari, B.-M., 2008. ALTERNATIVE MATERIALS FOR ADSORPTION OF HEAVY METALS AND PETROLEUM HYDROCARBONS FROM CONTAMINATED LEACHATES.

Environmental Technology, Volum 29, pp. 111-122.

Kardam, A., Rohit Raj, K., Srivastava, S. \& Srivastava, M. M., 2014. Nanocellulose fibers for biosorption of cadmium, nickel, and lead ions from aqueous solution. Clean Technologies and Environmental Policy, 16(2), p. 385-393.

Khorzughy, S. H., Eslamkish, T., Ardejani, F. D. \& Heydartaemeh, M. R., 2015. Cadmium removal from aqueous solutions by pumice and nano-pumice. Korean Journal of Chemical Engineering, 32(1), pp. 88-96.

Kurita, K., Sannan, T. \& Iwakura, Y., 1979. Studies on chitin. VI. Binding of metal cations. Journal of Applied Polymer Science, 23(2), p. 511-515.

Lee, J. H. \& Bang, K. W., 2000. CHARACTERIZATION OF URBAN STORMWATER RUNOFF. Water Research, 34(6), pp. 1773-1780.

Lee, J. H. et al., 2002. First flush analysis of urban storm runoff. The Science of the Total Environment, Volum 293, pp. 163-175.

Lemos, V. A. et al., 2007. Application of polyurethane foam as a sorbent for trace metal preconcentration - A review. Spectrochimica Acta Part B, Volum 62, p. 4-12.

Li, Q., Dunn, E. T., Grandmaison, E. W. \& Goosen, M. F. A., 1992. Applications and Properties of chitosan. Journal of Bioactive and Compatible Polymers, 7(4), pp. 370-397.

Liu, Z.-r.et al., 2008. Competitive adsorption of heavy metal ions on peat. Journal of China University of Mining and Technology, 18(2), pp. 255-260.

Li, W. \& Liu, S., 2012. Preparation and characterization of polyurethane foam/activated carbon composite adsorbents. Journal of Porous Materials, Volum 19, p. 567-572.

Makropoulos, C. K. \& Butler, D., 2010. Distributed Water Infrastructure for Sustainable Communities. Water Resour Manage, 24(11), p. 2795-2816. 
Peñarrocha, D., Estrela, M. J. \& Millán, M., 2002. CLASSIFICATION OF DAILY RAINFALL PATTERNS IN A MEDITERRANEAN AREA WITH EXTREME INTENSITY LEVELS: THE VALENCIA REGION. INTERNATIONAL JOURNAL OF CLIMATOLOGY, Volum 22, p. 677-695.

Pivarčiová, L., Rosskopfová, O., Galamboš, M. \& Rajec, P., 2014. Sorption of nickel on chitosan. Journal of Radioanalytical and Nuclear Chemistry, 300(1), pp. 361-366.

Potgieter, J. H., Potgieter-Vermaak, S. S. \& Kalibantonga, P. D., 2006. Heavy metals removal from solution by palygorskite clay. Minerals Engineering, 19(5), p. 463-470.

Ravi Kumar, M. N. V., 2000. A review of chitin and chitosan applications. Reactive \& Functional Polymers, Volum 46, p. 1-27.

Rinaudo, M., 2006. Chitin and chitosan: properties and applications. Progress in polymer science, 31(7), pp. 603-632.

Sen Gupta, B., Curran, M., Hasan, S. \& Ghosh, T. K., 2009. Adsorption characteristics of $\mathrm{Cu}$ and Ni on Irish peat moss. Journal of Environmental Management, 90(2), p. 954-960.

Søberg, L., 2014. Metal Pathways in Stormwater Treatment Systems. Luleå: Luleå University of Technology.

Täljemark, K. et al., 2004. Heavy metal and PAH sorption by pine bark. A: In Seventh International In Situ and On-Site Bioremediation Symposium, Orlando, Florida, USA, 2-5 June 2003. Part O.

Landfarming, Biopiles, Composting and Bioreactors. Battelle Press. s.I.:s.n.

Vaze, J. \& Chiew, F. H. S., 2003. Comparative evaluation of urban storm water quality models. WATER RESOURCES RESEARCH, 39(10), pp. 1280-1290.

Vaze, J. \& Chiew, F. H. S., 2003. Study of pollutant washoff from small impervious experimental. WATER RESOURCES RESEARCH, 39(6), pp. 1160-1170.

Wu, P. \& Zhou, Y.-s. Z., 2009. Simultaneous removal of coexistent heavy metals from simulated urban stormwater using four sorbents: A porous iron sorbent and its mixtures with zeolite and crystal gravel. Journal of Hazardous Materials, Volum 168, p. 674-680. 


\section{APPENDIX}

\section{First test session}

\section{" $A$ " filter cassette $-13 \mathrm{l} / \mathrm{min}$}

\begin{tabular}{|c|c|c|c|c|c|c|c|}
\hline & & $\mathbf{P b}$ & $\mathrm{Cu}$ & $\mathrm{Zn}$ & $\mathrm{Ni}$ & $\mathrm{Cd}$ & $\mathrm{Cr}$ \\
\hline 1 & Pine Bark & $30,0 \%$ & $6,8 \%$ & $5,0 \%$ & $-5,1 \%$ & $9,7 \%$ & $31,4 \%$ \\
\hline 2 & PUF (Coarse / Medium) & $46,8 \%$ & $3,5 \%$ & $-0,4 \%$ & $-2,2 \%$ & $1,7 \%$ & $16,0 \%$ \\
\hline 3 & PUF (AC / Fine) & $42,5 \%$ & $2,6 \%$ & $1,3 \%$ & $-0,6 \%$ & $1,6 \%$ & $28,0 \%$ \\
\hline 4 & PUF (AC / Medium) & $-30,7 \%$ & $38,5 \%$ & $1,6 \%$ & $1,3 \%$ & $5,7 \%$ & $-9,9 \%$ \\
\hline 5 & Air blown PPE & $21,7 \%$ & $17,0 \%$ & $3,2 \%$ & $1,3 \%$ & $13,8 \%$ & $19,6 \%$ \\
\hline 6 & PUF (AC / Coarse) & $-147,6 \%$ & $-7,3 \%$ & $-0,3 \%$ & $1,2 \%$ & $1,7 \%$ & $-29,9 \%$ \\
\hline 7 & Recycled PU granulate & $-3,6 \%$ & $20,5 \%$ & $-3,1 \%$ & $-1,1 \%$ & $4,1 \%$ & $-31,0 \%$ \\
\hline 8 & Bark/Chitosan & $55,0 \%$ & $34,1 \%$ & $0,8 \%$ & $-0,5 \%$ & $5,4 \%$ & $41,8 \%$ \\
\hline 9 & PUF (Coarse) + NC (Nano-cellulose) & $-39,8 \%$ & $5,6 \%$ & $-1,5 \%$ & $1,2 \%$ & $-3,2 \%$ & $26,9 \%$ \\
\hline 10 & Bark/Chitosan just sprayed & $-41,4 \%$ & $-12,5 \%$ & $2,1 \%$ & $3,3 \%$ & $-3,2 \%$ & $-133,3 \%$ \\
\hline 11 & PUF ( AC/ Fine/ Medium/ Coarse) & $-123,6 \%$ & $-30,2 \%$ & $-5,9 \%$ & $-13,4 \%$ & $-2,6 \%$ & $-74,1 \%$ \\
\hline 14 & GFH + Recycled PU granulate & $7,9 \%$ & $13,4 \%$ & $0,8 \%$ & $-0,5 \%$ & $-1,2 \%$ & $15,6 \%$ \\
\hline 18 & NC + PUF (Coarse) + Air blown PPE & $-41,1 \%$ & $3,7 \%$ & $5,3 \%$ & $1,5 \%$ & $4,8 \%$ & $-18,6 \%$ \\
\hline 19 & Recycled PU powder & $6,4 \%$ & $-17,8 \%$ & $13,4 \%$ & $12,4 \%$ & $11,0 \%$ & $-20,8 \%$ \\
\hline
\end{tabular}

\section{"A" filter cassette $-60 \mathrm{l} / \mathrm{min}$}

\begin{tabular}{|c|c|c|c|c|c|c|c|}
\hline & & $\mathbf{P b}$ & $\mathrm{Cu}$ & $\mathrm{Zn}$ & $\mathrm{Ni}$ & Cd & $\mathrm{Cr}$ \\
\hline 13 & Pine Bark & $15,5 \%$ & $3,1 \%$ & $-0,3 \%$ & $0,8 \%$ & $-2,2 \%$ & $10,8 \%$ \\
\hline 15 & Air blown PPE + PUF (AC) & $-32,1 \%$ & $-0,1 \%$ & $12,2 \%$ & $10,8 \%$ & $14,6 \%$ & $-40,2 \%$ \\
\hline 16 & GFH & $-15,7 \%$ & $1,9 \%$ & $3,4 \%$ & $2,4 \%$ & $8,1 \%$ & $-30,8 \%$ \\
\hline 17 & GFH + Recycled PU granulate & $29,9 \%$ & $45,3 \%$ & $-2,1 \%$ & $-0,7 \%$ & $-3,4 \%$ & $26,3 \%$ \\
\hline 20 & PUF (AC / Medium) & $84,4 \%$ & $4,6 \%$ & $3,0 \%$ & $3,7 \%$ & $7,0 \%$ & $-85,1 \%$ \\
\hline
\end{tabular}


“B" filter cassette $-13 \mathrm{l} / \mathrm{min}$

\begin{tabular}{|c|c|c|c|c|c|c|c|}
\hline & & $\mathrm{Pb}$ & $\mathrm{Cu}$ & Zn & $\mathbf{N i}$ & Cd & $\mathrm{Cr}$ \\
\hline 12 & Pine Bark & $-44,7 \%$ & $14,5 \%$ & $-0,9 \%$ & $-1,8 \%$ & $0,4 \%$ & $-13,0 \%$ \\
\hline 21 & Bark/Chitosan & $-23,0 \%$ & $-28,2 \%$ & $-21,2 \%$ & $-19,3 \%$ & $-18,0 \%$ & $3,0 \%$ \\
\hline 23 & Pine bark + GFH & $13,5 \%$ & $15,5 \%$ & $4,9 \%$ & $-4,2 \%$ & $10,7 \%$ & $79,3 \%$ \\
\hline 27 & Pine bark + Recycled PU granulate & $-45,1 \%$ & $1,3 \%$ & $14,2 \%$ & $5,8 \%$ & $13,8 \%$ & $-35,1 \%$ \\
\hline 29 & Recycled PU granulate & $19,7 \%$ & $-3,3 \%$ & $-2,4 \%$ & $-2,1 \%$ & $-0,5 \%$ & $18,1 \%$ \\
\hline
\end{tabular}

"A1" filter cassette $-60 \mathrm{I} / \mathrm{min}$

\begin{tabular}{|c|c|c|c|c|c|c|c|}
\hline & & $\mathrm{Pb}$ & $\mathrm{Cu}$ & $\mathrm{Zn}$ & $\mathbf{N i}$ & Cd & $\mathrm{Cr}$ \\
\hline 22 & Pine Bark & $-336,9 \%$ & $-54,3 \%$ & $-36,1 \%$ & $-30,5 \%$ & $-30,2 \%$ & $-19,7 \%$ \\
\hline 24 & PUF (AC / Fine) & $-62,5 \%$ & $-9,4 \%$ & $0,8 \%$ & $-3,0 \%$ & $2,0 \%$ & $-55,2 \%$ \\
\hline 25 & Pine bark + GFH & $34,8 \%$ & $-3,3 \%$ & $4,6 \%$ & $5,8 \%$ & $-0,4 \%$ & $14,3 \%$ \\
\hline 26 & Pine bark + Recycled PU granulate & $24,5 \%$ & $3,1 \%$ & $-5,9 \%$ & $-4,7 \%$ & $-4,2 \%$ & $30,2 \%$ \\
\hline 28 & Recycled PU granulate & $29,1 \%$ & $7,5 \%$ & $6,8 \%$ & $6,5 \%$ & $4,1 \%$ & $14,7 \%$ \\
\hline 30 & Pine bark + AC PUF & $-21,0 \%$ & $0,7 \%$ & $-0,3 \%$ & $1,0 \%$ & $5,4 \%$ & $-17,6 \%$ \\
\hline 31 & Air blown PPE & $14,6 \%$ & $0,2 \%$ & $12,4 \%$ & $18,6 \%$ & $14,4 \%$ & $-13,7 \%$ \\
\hline 32 & PUF (AC / Coarse) & $7,4 \%$ & $3,3 \%$ & $3,4 \%$ & $1,2 \%$ & $2,6 \%$ & $14,8 \%$ \\
\hline 33 & PUF (Coarse / Medium) & $13,9 \%$ & $5,7 \%$ & $3,9 \%$ & $4,7 \%$ & $2,2 \%$ & $11,2 \%$ \\
\hline 34 & PUF (Coarse) + NC (Nano-cellulose) & $-36,8 \%$ & $-6,5 \%$ & $-0,9 \%$ & $0,4 \%$ & $-3,7 \%$ & $-5,2 \%$ \\
\hline
\end{tabular}

“C" filter cassette $-60 \mathrm{I} / \mathrm{min}$

\begin{tabular}{|c|c|c|c|c|c|c|c|}
\hline & & $\mathrm{Pb}$ & $\mathrm{Cu}$ & Zn & $\mathrm{Ni}$ & Cd & $\mathrm{Cr}$ \\
\hline 35 & Acitex round-flat filter & $26 \%$ & $37 \%$ & $-17 \%$ & $8 \%$ & $-6 \%$ & $8 \%$ \\
\hline 36 & Acitex round-flat filter (Black layer) & $-121 \%$ & $17 \%$ & $-32 \%$ & $0 \%$ & $-17 \%$ & $-122 \%$ \\
\hline
\end{tabular}




\section{Second test session}

"A1" filter cassette $-9 \mathrm{l} / \mathrm{min}$

\begin{tabular}{|c|c|c|c|c|c|c|c|}
\hline & & $\mathbf{P b}$ & $\mathrm{Cu}$ & $\mathrm{Zn}$ & $\mathbf{N i}$ & Cd & $\mathrm{Cr}$ \\
\hline 9 & Peat & $-30 \%$ & $-15 \%$ & $-26 \%$ & $-26 \%$ & $-27 \%$ & $-49 \%$ \\
\hline 16 & Pine Bark + Peat & $41 \%$ & $19 \%$ & $3 \%$ & $-1 \%$ & $7 \%$ & $10 \%$ \\
\hline 21 & Absol + Peat & $14 \%$ & $32 \%$ & $15 \%$ & $12 \%$ & $16 \%$ & $18 \%$ \\
\hline
\end{tabular}

"A2" filter cassette $-3 \mathrm{l} / \mathrm{min}$

\begin{tabular}{|c|c|c|c|c|c|c|c|}
\hline & 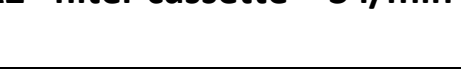 & $\mathbf{P b}$ & $\mathrm{Cu}$ & Zn & $\mathbf{N i}$ & Cd & $\mathrm{Cr}$ \\
\hline 23 & Pine Bark + Clay & $-102 \%$ & $-5 \%$ & $-2 \%$ & $-2 \%$ & $-5 \%$ & $-8 \%$ \\
\hline 24 & Peat & $82 \%$ & $40 \%$ & $19 \%$ & $11 \%$ & $13 \%$ & $62 \%$ \\
\hline 25 & Pine Bark + Pumice & $57 \%$ & $-57 \%$ & $-86 \%$ & $-77 \%$ & $-76 \%$ & $35 \%$ \\
\hline 26 & Pine Bark + Peat & $70 \%$ & $24 \%$ & $-3 \%$ & $-8 \%$ & $-4 \%$ & $41 \%$ \\
\hline 27 & Pine Bark + Peat + Clay & $36 \%$ & 125 & $6 \%$ & $8 \%$ & $9 \%$ & $24 \%$ \\
\hline 29 & Pine bark & $-22 \%$ & $-50 \%$ & $-12 \%$ & $-3 \%$ & $-11 \%$ & $-79 \%$ \\
\hline 31 & Pine Bark and Chitosan & $35 \%$ & $27 \%$ & $20 \%$ & $20 \%$ & $21 \%$ & $16 \%$ \\
\hline 33 & Peat and Chitosan & $3 \%$ & $-2 \%$ & $-4 \%$ & $-5 \%$ & $-5 \%$ & $1 \%$ \\
\hline
\end{tabular}

\section{"B" filter cassette $-3 \mathrm{l} / \mathrm{min}$}

\begin{tabular}{|c|c|c|c|c|c|c|c|}
\hline & & $\mathrm{Pb}$ & $\mathrm{Cu}$ & $\mathrm{Zn}$ & $\mathbf{N i}$ & Cd & $\mathrm{Cr}$ \\
\hline 30 & Pine bark & - & - & - & - & - & - \\
\hline 32 & Pine Bark and Chitosan & $56 \%$ & $22 \%$ & $12 \%$ & $13 \%$ & $11 \%$ & $21 \%$ \\
\hline
\end{tabular}

